\title{
MANCHESTER
}

1824

눈

Economics

Discussion Paper Series EDP-1304

\section{Sports League Quality, Broadcaster TV Rights Bids and Wholesale Regulation of Sports Channels}

\author{
Paul Madden
}

Mario Pezzino

March 2013

Economics

School of Social Sciences

The University of Manchester

Manchester M13 9PL 


\title{
SPORTS LEAGUE QUALITY, BROADCASTER TV RIGHTS BIDS AND WHOLESALE REGULATION OF SPORTS CHANNELS
}

\author{
Paul Madden and Mario Pezzino \\ University of Manchester
}

\begin{abstract}
In a complete information auction, two integrated broadcasters bid for exclusive TV-rights to a sports league (e.g. the English Premier League), with two potential externalities: receipts feed through to the two league clubs who choose player expenditures, possibly enhancing league quality and the resulting sports channel (e.g. Sky Sports); also the right's winner either offers the channel wholesale creating a product-differentiated retail duopoly, or forecloses. Under laissez-faire, outcomes can be "quality-driven" or "rivaldriven" depending on league/broadcaster parameters and auction protocol, and foreclosure never happens. Ofcom's suggested wholesale regulation of Sky Sports typically reduces league rights income, quality and consumer surpluses.
\end{abstract}

\section{JEL classification numbers; L10, L83}

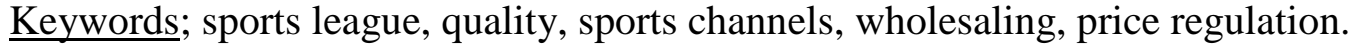

Acknowledgment We thank Thomas Peeters and Helen Weeds for some helpful comments and conversations on the first version of the paper. Similar thanks to Tommaso Valletti (discussant), and other participants in the European Association for Research in Industrial Economics (EARIE) conference in Stockholm, September 2011. A more recent version has also benefitted significantly from comments from seminar participants at the Universities of Leicester, Manchester and Newcastle. Any omissions and shortcomings remain the authors' responsibility. 


\section{INTRODUCTION}

The paper is motivated by the following history. First, in a number of auctions of TV rights to coverage of soccer's English Premier League (EPL) since 1992, Sky has won more or less exclusive rights, paying large and increasing sums to the league and hence to its clubs ${ }^{1}$. It is widely accepted that this money has led to a significant increase in player quality, and player salaries, the EPL now being the club base for many of the world's most talented players. In turn, this extra quality has no doubt increased the attractiveness of Sky Sports (the channel which carries the EPL games) to Sky's pay-TV consumers, and to rival broadcasters wishing to purchase the channel wholesale for sale to their own consumers. Secondly, in March 2010, the UK regulator Ofcom (see Ofcom (2010)), concerned inter alia about the relative lack of wholesaling of Sky Sports, imposed regulations whereby wholesaling of the channel must be offered to rivals ("wholesale-must-offer", WMO), with a margin between Sky's own retail price and its wholesale price that exceeds some minimum level (margin regulation for short ${ }^{2}$ ). Thirdly, in August 2012, after appeals against the Ofcom ruling, a Competition Appeal Tribunal (CAT - see CAT (2012)) over-ruled the decision as it found no evidence of Ofcom's key reasons for intervention, namely Sky's intention to withhold from wholesaling negotiations with rivals. Ofcom's suggested regulations are currently in abeyance.

Against this background, we present a Game-theoretic ${ }^{3}$ model that integrates a sports league and a pay-TV broadcasting sector bidding for exclusive ${ }^{4}$ league TV rights, and incorporates the quality dimensions mentioned above. The focus is the nature of equilibrium under laissezfaire, and then the positive and normative consequences of Ofcom's suggestions; the conclusions regarding the latter will be quite negative.

The Game has 3 stages and 4 Players; 2 clubs (and their owners) in the league and 2 broadcasters, with associated consumers and players. Laissez-faire evolves as follows.

(i) At stage I, the 2 vertically integrated, profit-maximizing broadcasters bid for the exclusive league TV rights. Bids are submitted to the league (as is the EPL case), rather than to individual clubs separately ${ }^{5}$. Rights are allocated via a first (FPSB) or second (SPSB) price sealed bid auction, with complete information.

(ii) Club decisions are made at stage II. The 2 clubs play each other twice (home and away), and choose their expenditure on playing talent and consumer ticket prices for stadium viewing of their home game, deriving income from ticket sales ("gate revenue"). Clubs also

\footnotetext{
${ }^{1}$ BSkyB won $100 \%$ exclusive rights between 1992 and 2007, with bids (per game) of: $£ 633,000,1992-97 ; £ 2.79$ million, 1997-2000; £3.64 million, 2000-04; £2.47 million, 2004-07. After 2007 and EU intervention, complete exclusivity was not allowed, but Sky has retained rights to at least $75 \%$ of games with winning bids per game of: $£ 4.12$ million, 2007-10; £4.3 million, 2010-13; £6.53 million, 2013-16. See Gratton and Solberg (2007).

2 Ofcom (2010, p. 14, 501-502) motivates its decision to adopt margin regulation instead of cost-plus pricing via the desire to avoid decreasing the profitability of owning the TV-rights, and consequently to avoid negative effects both on the sports industry (that may be caused by lower investments in talent by clubs) and the broadcasting industry (that may be caused by lower investments in sports channel quality). The desirability of margin regulation (often referred as retail minus pricing) compared to cost-plus pricing in terms of creating incentives to the integrated firms to improve the quality of the essential input is clearly established in the literature (see for example Sarmento and Brandão (2007)). For a review of the literature of access price regulation, see Armstrong (2002), Laffont and Tirole (2004), and Armstrong and Sappington (2007).

${ }^{3}$ Certain terms (e.g. game, player) have different meanings in the sports context from the economic model context. Capital letters are used to indicate the latter.

${ }^{4}$ As per footnote 1 , this is a simplifying assumption, but a good first approximation.

5 Falconieri et al. (2004) provide an interesting cooperative Game analysis of collective (league) versus individual club bargaining with a broadcaster. There is only one broadcaster, so wholesaling is absent; in turn, we simply make the collective assumption throughout, reflecting the EPL reality.
} 
receive broadcaster revenue - the league distributes its rights income to clubs via a performance-based rule (partly true for the EPL). There is a supply curve of playing talent to the league and the wage per unit of talent adjusts to clear the talent market given club expenditures, producing talent allocations to clubs and the league which define club and league qualities. Clubs have the assumed owner objective of maximizing team quality subject to a non-negative profit constraint ("win-maximization"), usually taken to be more plausible than profit maximization for the European soccer context ${ }^{6}$; increased club revenues may then feed through to increased club and league qualities, to some extent.

(iii) At stage III, the rights winning broadcaster produces a sports channel which covers the games, and which may be sold wholesale to the loser, or the loser may be foreclosed from access. One or both broadcasters then sell the channel (product differentiated) to pay-TV consumers. The rights winner chooses its retail price under foreclosure; if not, the winner chooses its wholesale price and its retail price, after which the loser announces its retail price.

With regulation the Game changes at stage III; foreclosure is not allowed, and the right's winner's retail-wholesale margin must exceed the regulatory minimum.

The paper impinges on several literatures - auctions at stage I, sports leagues at stage II, and, at stage III, broadcasting and wholesaling - and provides various novel features and insights.

The league rights income decided at stage I may enhance league quality (at stage II, via club decisions), creating a more attractive sports channel (at stage III) for both the auction loser (buying wholesale) and the winner. Our complete information auction is similar to Armstrong (1999), Harbord and Ottaviani (2001, 2002) and Ettinger (2010) with respect to the downstream externality on the loser, but also has the indirect quality effect on the winner itself, whose magnitude is endogenous ${ }^{7}$. This creates the possibility (under FPSB) of what we call quality-driven equilibrium (QDE), where the winner's bid is higher than the rival for quality enhancement reasons, as opposed to rival-driven equilibrium (RDE) where this is not so; only RDE is possible under SPSB. Whether QDE or RDE emerges under laissez-faire depends on various parameters, and the impact of regulation will also depend on this.

Modelling labour markets as talent markets with a given talent supply curve (as in efficiency labour models) is common in the sports league literature ${ }^{8}$, but is mostly focused on the extremes of perfect inelasticity for North American leagues with little inter-league talent

\footnotetext{
${ }^{6}$ Kesenne (2007) contains extensive accounts of the theory of sports leagues with win-maximizing (and profitmaximizing) clubs. Garcia-del-Barrio and Szymanski (2009) provide empirical evidence for win-maximization rather than profit-maximization in Spanish soccer. Recently alternative club objectives for European soccer have been suggested; fan welfare maximization in Madden (2012), utility maximization in Madden and Robinson (2012), sugar-daddy or benefactor behaviour in Lang. et al. (2010), Madden (2013). We do not think these alternatives would change the qualitative nature of our main conclusions, and the imminent imposition of Financial Fair Play regulation on European soccer clubs should make leagues (ex post) approximate better leagues of win maximizers, as assumed here - see Madden (2013).

${ }^{7}$ There is a wider literature on incomplete information auctions with externalities, e.g. Jehiel and Moldovanu (2006), Lu (2012), Maasland and Onderstal (2007). And there are several papers that endogenise channel quality in broadcaster models, but with that quality under direct broadcaster control; Armstrong (2005), Armstrong and Weeds (2007), Seabright and Weeds (2007), Stennek (2007), Weeds (2011).

${ }^{8}$ In their interesting and related paper, and with a somewhat different player labour market, Palomino and Sakovics (2004) take broadcast income to be an exogenous function of game quality, and analyse league decisions on how such income would be shared between clubs that interact strategically in the labour market. Instead we take as given the broadcast income sharing rule, and bring the broadcasters into the strategic interactions, thus endogenising the relation between broadcast income and quality.
} 
competition, and perfect elasticity for the competitive European soccer context. ${ }^{9}$ We generalise with a constant elastic talent supply that may not be perfectly elastic, and reiterate the importance of this elasticity for broadcaster regulation questions, already noted for club player expenditure regulation ("Financial Fair Play") by Madden (2013).

The possibility of market size expansion and the extent of pay-TV market competition were important in Ofcom's deliberations. We adopt a simple, but non-standard specification for pay-TV consumer demand at stage III that allows total market size to vary, and also allows the extent of retail market competition to vary across the entire range from perfect competition to monopoly ${ }^{10}$. A quite general impossibility of laissez-faire foreclosure emerges, irrespective of the extent of retail competition, making WMO redundant ${ }^{11}$. Margin regulation may well affect league rights income and quality, as well as retail prices. Neither effect is favourable for stadium or pay-TV consumers; aggregate consumer surplus certainly falls. An alternative direct regulation of the wholesale price does better on prices (where a more general argument is again available) but worse on quality.

The basic framework is described in Section 2, and Section 3 analyses laissez-faire. Margin regulation is the subject of Sections 4 and 5. Section 6 looks at wholesale price regulation, and Section 7 concludes. The appendix contains proofs of Lemmas and Propositions.

\section{THE BASIC FRAMEWORK}

The 3-stage Game will involve 2 win-maximizing clubs in a sports league, denoted $i=1,2$, and 2 profit-maximizing broadcasters, denoted bi, $i=1,2$, as follows.

\subsection{Stage I: the auction}

The league offers exclusive rights for auction, with 0 reserve, and the 2 broadcasters submit simultaneously non-negative bids $b_{i}$ from bi, $i=1,2$. If the auction is FPSB, rights are awarded to the broadcaster with the strictly higher bid, if there is one, paying $b=\max \left(b_{1}, b_{2}\right)$; if $b=b_{1}=b_{2}$, there is a tie-break rule, described below. Under SPSB ${ }^{12}$, rights are again awarded to the broadcaster with the strictly higher bid, now paying $b=\min \left(b_{1}, b_{2}\right)$, and again the tie-break is explained later. Thus, in both cases, we are assuming collective sale of rights by the league, consistent with current EPL practice, rather than separate sale of home game rights by individual clubs. The league then distributes the proceeds from the sale to clubs in the league at Stage II.

\footnotetext{
${ }^{9}$ See Dietl et al. (2009), Lang et al. (2011), Madden (2012), Madden and Robinson (2012). These papers are largely focused on consequences of alternative owner objectives, but not broadcasting.

10 The standard Hotelling or Salop alternatives have been used in a number of broadcaster papers (Armstrong (1999, 2005), Armstrong and Weeds (2007), Harbord and Ottaviani (2001), Seabright and Weeds (2007), Stennek (2007), Weeds (2011)) but usually need to limit the range of competition with restrictions on transport cost parameters, and/or assume covered markets with no expansion possibility.

${ }^{11}$ From a large literature the most adjacent similar result is in Harbord and Ottaviani (2001). This and some more recent wholesaling/foreclosure literature is returned to later: Bourreau et al. (2011), Hoffler and Schmidt (2008), Hombert et al. (2009), Ordover and Shaffer (2007).

${ }^{12}$ We carry both FPSB and SPSB through the analysis as it is not clear that a uniform assumption of one or the other fits well the history of EPL auctions. Indeed the first 2 rights allocations were quite informal (Horsman, 1998, p. 90-105, 161-169), perhaps approximating better SBSB than FPSB (MMC, 1999, p. 116-120, especially paragraph 4.144); see also Armstrong (1999, p.261-2). After EU intervention noted in footnote 1, games were packaged and EPL made commitments (in 2006), including the award of "each Package of Rights to the Bidder with the highest...bid for that Package"; so FPSB is the more likely match for at least the last 3 auctions.
} 


\subsection{Stage II: club decisions on player expenditure and ticket prices}

Playing talent is available to the league in constant elastic supply $S(w)=w^{\varepsilon}$ where $w$ is the wage per unit of talent ${ }^{13}$. The 2 clubs in the league play each other twice, once at home and once away, in stadiums of given large capacity. $t_{i}$ denotes club $i$ 's quantity of talent, alternatively the quality of its team, and $e_{i}=w t_{i}$ is the expenditure on talent; $T=t_{1}+t_{2}$ and $E=e_{1}+e_{2}$ are corresponding aggregates. $W_{i}=t_{i} / T=e_{i} / E, i=1,2$ is club $i$ 's relative quality or "win percentage", an indicator of the "competitive balance" in the league. The talent market clears with a wage ${ }^{14} w=E / S(w)=E^{\frac{1}{1+\varepsilon}}$, giving talent allocations $t_{i}=e_{i} / E^{\frac{1}{1+\varepsilon}}$ and $T=E^{\frac{\varepsilon}{1+\varepsilon}}$. The hiring of talent is the only club cost. Notice that at the limit $\varepsilon=0$ changes in $E$ produce no change in aggregate league quality $(T)$ merely inflating player salaries (via $w$ ), whereas at $\varepsilon=\infty$ there is no salary inflation and a 1-1 increase in quality.

Clubs earn gate revenue from their home game, selling tickets (at prices $p_{i}, i=1,2$ ) for direct stadium (rather than TV) viewing of the game. In their "Tale of two audiences" paper, Buraimo and Simmons (2009) provide evidence that stadium and TV consumers are quite different in their characteristics, and we model them as disjoint sets. Stadium consumers are thus thought of as partisan, "hard-core" home team fans, for whom pay-TV is not an alternative, deriving utility $c_{i}-y_{i}-p_{i}, i=1,2$, where $y_{i} \geq 0$ is a heterogeneity parameter and $c_{i}=2 T^{\frac{1}{2} \sigma} d\left(W_{i}\right)^{\frac{1}{2}}$ is the maximum ticket valuation, or choke price. There is a mass of $\mu_{i} y_{i}$ fans with heterogeneity less than $y_{i}$, generating ticket demand functions;

$$
D_{i}\left(p_{i}, c_{i}\right)=\mu_{i}\left(c_{i}-p_{i}\right), i=1,2
$$

Thus ticket demand is linear in price, and changes in the talent allocations produce parallel shifts in the demand curve, via $c_{i}$. For given price and win percentages, demand increases with the aggregate quality $T$, with an elasticity measured by $\sigma / 2$, where $\sigma \in(0,1) . d\left(W_{i}\right)$ is assumed to be strictly concave with $d(0)=0$ (no fan wants to watch a talentless team), $d^{\prime}(0)=\infty$ (an inessential Inada condition), and with a maximum at $W_{i}=\omega \in\left(\frac{1}{2}, 1\right)$. The last of these assumptions is again common in the sports economics literature ${ }^{15}$ to reflect the assumed partisan nature of stadium consumers, who prefer games that their team is more likely to win, but only to an extent as too one-sided games become uninteresting. $\mu_{i}>0, i=1,2$ measure the potential stadium attendance (the club's "fanbase"); without loss of generality club 1 is the bigger club with $\mu_{1}>\mu_{2}$.

Clubs also receive broadcaster revenue, as a share of the league's rights income $(b)$. We assume that the sharing rule is purely performance based ${ }^{16}$, as measured by its relative

\footnotetext{
${ }^{13}$ Individual players have exogenous talent and receive a salary of (talent)x(wage per unit of talent).

${ }^{14}$ As in strategic market Games, the wage is the ratio of "bids" $E$ to "offers" $S(w)$. Madden (2011) argues generally for the strategic market Game approach to sports league labour markets.

${ }^{15}$ Much of this literature by-passes ticket price decisions and starts from club revenue functions which are, rather strangely, homogeneous of degree 0 in talent levels. Madden (2011) suggests an alternative, homogeneous of degree $\sigma \in(0,1)$ specification. The reason for the functional form for $c_{i}$ is that it also leads to this alternative revenue function $\left(\mu_{i} T^{\sigma} d\left(W_{i}\right)\right.$ in (3.1) below when (3.2) is imposed).

${ }^{16}$ Currently the EPL sharing rule is $50 \%$ performance based.
} 
quality, namely that club $i$ receives $W_{i} b$. Thus profits are gate revenue plus broadcaster revenue less talent expenditure;

$$
\pi_{i}=p_{i} D_{i}\left(p_{i}, c_{i}\right)+W_{i} b-e_{i}, i=1,2
$$

Clubs choose $p_{i}$ and $e_{i}$ simultaneously with the assumed win maximization owner objective - maximization of team quality $\left(t_{i}\right)$ subject to a non-negative profit constraint $\left(\pi_{i} \geq 0\right)$.

\subsection{Stage III: broadcaster foreclosure and price decisions}

At stage III under laissez-faire, the rights winner (bi, $i=1$ or 2 ) can offer the resulting sports channel wholesale to the loser at price $h_{i}$ per viewer ${ }^{17}$, or can foreclose on the loser and enjoy a monopoly position in the retail market; if wholesaling occurs, both broadcasters then sell the channel to pay-TV consumers. We propose a simple microfoundation for retail demand. We think of the relatively homogeneous sports channel as providing 1 of 2 characteristics of the products offered. The second differentiated characteristic might be associated with differing delivery technologies (maybe different platforms), or some bundling of the sports channel with other channels - we do not make this explicit, but assume that all consumers have a valuation for the products offered by b1 and b2 which are (heterogeneous) weighted averages of characteristics utility, as follows. Assume there are 2 types of consumers; those with a preference towards b1's product (type 1) and those who favour that of b2 (type 2). $x_{i} \geq 0$ is a heterogeneity parameter for each consumer type, that indicates the relative weights on the sports channel and the other characteristic in the following specification of utilities for type i consumers buying from bi, $U_{i i}\left(x_{i}\right)$, and from $\mathrm{bj}, U_{i j}\left(x_{i}\right)$ :

$$
U_{i i}\left(x_{i}\right)=\lambda\left(x_{i}\right) v+\left[1-\lambda\left(x_{i}\right)\right] h-s_{i} ; U_{i j}\left(x_{i}\right)=\lambda\left(x_{i}\right) v+\left[1-\lambda\left(x_{i}\right)\right] l-s_{j}
$$

Here $s_{i}$ is the cost of acquiring the sports channel from bi, $v>0, v>h>l$ and $\lambda\left(x_{i}\right)=1-x_{i}$. Think of $v, h, l$ respectively as utilities associated with the sports channel, the more preferred second characteristic and the less preferred one; The specification is then that utility is a weighted average of the relevant 2 numbers, with weight all on the sports channel if $x_{i}=0$ and all on the other characteristic if $x_{i}=1$. To economise on notation, let $\delta \equiv h-l$ and $h=v-1$, so that $(2.3)$ becomes, for any $\delta \in(0, \infty)$ and $v>0$;

$$
U_{i i}\left(x_{i}\right)=v-x_{i}-s_{i} ; U_{i j}\left(x_{i}\right)=v-(1+\delta) x_{i}-s_{i}
$$

$v$ is taken to be $v=2 T^{\frac{1}{2} \sigma} d_{b}\left(W_{1}\right)^{\frac{1}{2}}$, similar to $c_{i}$ for stadium fans, where $d_{b}\left(W_{1}\right)$ has similar properties and plays a similar role to $d\left(W_{i}\right)$ earlier ${ }^{18}$. The assumption that $v$ is the same for both consumer types is important (see sections 3.2, 3.3), but is natural - there seems no reason for assuming (say) that consumers who favour (in our sense) b1 derive systematically higher or lower utility from watching the sports channel than those who favour b2.

\footnotetext{
${ }^{17}$ Sky has offered Sky Sports wholesale since 1995, via its so-called rate card tariff. Currently BT and Virgin Media do buy wholesale. Linear (rather than two-part) pricing has been the norm, and is what Ofcom assumed in its judgement. It is then natural for us to adopt this linear, price-per-viewer assumption.

${ }^{18}$ There is no reason to expect any partisan viewers to prefer one broadcaster to the other, so dependence is on $W_{1}$ rather than $W_{i}$. Also the mixed and perhaps non-partisan TV viewers would create a maximum for $d_{b}\left(W_{1}\right)$ closer to $1 / 2$.
} 
$\delta$ is an indicator of the extent of product differentiation, or pay-TV market competition; the limit $\delta=0$ is where the bundles are perfect substitutes and competition is perfect (homogeneous Bertrand), and the monopoly extreme appears as $\delta \rightarrow \infty$. There is a mass of $\beta_{i} x_{i}$ consumers with heterogeneity less than $x_{i}$, and $\beta_{1}>\beta_{2}$ so b1 has the bigger potential retail market, and is thought of as Sky. The purchase decision is dictated by $\max \left\{U_{i i}\left(x_{i}\right), U_{i j}\left(x_{i}\right), 0\right\}$, which provides the following formulae for broadcaster demands ${ }^{19}$ $i=1,2, j \neq i$;

$D_{b i}\left(s_{i}, s_{j}, v\right)=\left(\beta_{i}+\frac{1}{1+\delta} \beta_{j}\right)\left(v-s_{i}\right)$ if $0 \leq s_{i} \leq(1+\delta) s_{j}-\delta v$

$D_{b i}\left(s_{i}, s_{j}, v\right)=\beta_{i}\left(v-s_{i}\right)+\frac{1}{\delta} \beta_{j}\left(s_{j}-s_{i}\right)$ if $(1+\delta) s_{j}-\delta v<s_{i} \leq s_{j}$

$D_{b i}\left(s_{i}, s_{j}, v\right)=\beta_{i}\left[\left(v-s_{i}\right)-\frac{1}{\delta}\left(s_{i}-s_{j}\right)\right]$ if $s_{j} \leq s_{i}<\frac{1}{1+\delta} s_{j}+\frac{\delta}{1+\delta} v$

$D_{b i}\left(s_{i}, s_{j}, v\right)=0$ if $\frac{1}{1+\delta} s_{j}+\frac{\delta}{1+\delta} v \leq s_{i}$

$D_{b i}>0$ in (2.5)-(2.7), 0 in (2.8); $D_{b j}>0$ in (2.6)-(2.8), 0 in (2.5). At low $s_{i}$ in (2.5), bi takes the whole market of both consumer types. At slightly higher prices in (2.6), bi starts to lose some type $\mathrm{j}$ consumers to bj, but is still the lower price retailer, whilst in (2.7) bi offers the higher price and now has no type $\mathrm{j}$ customers, starting to lose some type i's to the rival. In (2.8), this loss is complete and bi gets no market share.

Under foreclosure of bj by bi, demand is given by (2.5) for all $s_{i}, 0 \leq s_{i} \leq v$.

Given its more efficient standalone usage of the rights (since $\beta_{1}>\beta_{2}$ ), we assume that the tie-break rule at Stage I is that b1 wins - as in asymmetric cost Bertrand Games where the more efficient firm takes the whole market.

The rights bid is the only cost for the rights winner (bi), and the wholesale cost is the only cost for the loser (bj), abstracting from production costs to simplify some of the derivations that follow (but see section 3.3). Profits are;

$$
\begin{gathered}
\pi_{b i}\left(s_{i}, s_{j}, v, h_{i}\right)=s_{i} D_{b i}\left(s_{i}, s_{j}, v\right)+h_{i} D_{b j}\left(s_{j}, s_{i}, v\right)-b_{i} \\
\pi_{b j}\left(s_{j}, s_{i}, v, h_{i}\right)=\left(s_{j}-h_{i}\right) D_{b j}\left(s_{j}, s_{i}, v\right)
\end{gathered}
$$

\section{LAISSEZ-FAIRE EQUILIBRIUM}

We look for subgame perfect equilibrium (SPE) of the Game under laissez-faire. Suppose the right's winner paid $b$ at stage I; stage II decisions on $p_{i}$ and $e_{i}$ do not depend on the broadcaster price decisions at stage III. It is then convenient to start the SPE derivation at stage II.

\footnotetext{
19 Our specification offers pluses and minuses compared to Hotelling/Salop alternatives. It does allow expansion in the pay-TV market (important to Ofcom) not afforded by covered Hotelling/Salop. It allows easy analysis of the entire range of retail market competition from perfect $(\delta=0)$ to monopoly $(\delta \rightarrow \infty)$; Harbord and Ottaviani (2001), and others, typically need not too much competition (measured by travel cost) to generate their results. A minus compared to Harbord and Ottaviani (2001) is the lack of detail on costs/benefits behind the second characteristic, explicit in Harbord and Ottaviani (2001) as basic (as opposed to premium, sports channel) programming. A possible further interesting feature of our specification is that, when $\beta_{i}=\beta_{j}$ (see (2.5)-(2.8)), the demands coincide with those generated by a quadratic utility function representative consumer, buying both goods, but in a model where a large number of consumers each buy one of the goods.
} 


\subsection{Club decisions}

From (2.1) and (2.2), the profits of club $i$ are;

$$
\pi_{i}=\mu_{i} p_{i}\left[2 T^{\frac{1}{2} \sigma} d\left(W_{i}\right)^{\frac{1}{2}}-p_{i}\right]+W_{i} b-e_{i}, i=1,2
$$

The win maximization objective implies that whatever $e_{i}$ is chosen will be coupled with the revenue maximizing ticket price, satisfying the usual unit demand elasticity;

$$
p_{i}=T^{\frac{1}{2} \sigma} d\left(W_{i}\right)^{\frac{1}{2}}, i=1,2
$$

Win maximization also implies that the choice of $e_{i}$ will make $\pi_{i}=0, i=1,2$. Substituting (3.2) into (3.1) and rearranging $\pi_{i}=0, i=1,2$ produces;

$$
\mu_{i} d\left(W_{i}\right) / W_{i}=(E-b) / T^{\sigma}, i=1,2
$$

With the talent market clearance condition, (3.2) and (3.3) define the stage II subgame equilibrium decisions by clubs, with the following features;

Lemma 1 If the right's winner paid $b$ at stage I, the stage II subgame equilibrium club decisions imply:

(a) unique win percentages $W_{1}^{*} \in\left(\frac{1}{2}, 1\right) \quad$ (with $W_{2}^{*}=1-W_{1}^{*}$ ), defined by $\mu_{1} d\left(W_{1}^{*}\right) / W_{1}^{*}=\mu_{2} d\left(1-W_{1}^{*}\right) /\left(1-W_{1}^{*}\right) \equiv \alpha$, where $W_{1}^{*}$ does not depend on $b$;

(b) a level of league quality defined by an increasing function $T(b)$ on domain $b \geq 0$, whose inverse function is $b(T)=T^{\frac{1+\varepsilon}{\varepsilon}}-\alpha T^{\sigma}$ on domain $T \geq \alpha^{\frac{\varepsilon}{1+\varepsilon-\varepsilon \sigma}} \equiv T_{\min }$.

$T_{\min }$ is the league quality that would emerge if clubs relied only on gate revenue $(b=0)$. As $b$ increases from 0 , the league quality increases - the win-maximizing clubs each increase their player expenditure and team quality from their increased broadcasting income, but in a way which leaves unchanged the win percentages, and so the league competitive balance. The latter invariance is due to the performance based rule assumed for the distribution of league broadcast income to clubs, which simplifies subsequent analysis ${ }^{20}$; it follows immediately that $W_{1}^{*}$ describes the $\mathrm{SPE}^{21}$ win percentages. Notice also that, since $W_{1}^{*}>\frac{1}{2}$, the bigger club will have the better team and higher win percentage, as usual in sports league models.

\subsection{Foreclosure or wholesale offer}

Suppose first that the large broadcaster b1 won the rights and paid $b$ at stage I, leading to $T=T(b)$ and $W_{1}^{*}$ at stage II. Then in the stage III subgame either b1 forecloses or b2 sets its retail price after b1 has announced its wholesale price offer and its retail price, with payoffs defined by (2.5)-(2.10).

Lemma 2 Given that b1 won the rights paying $b$ at stage I, and the resulting stage II subgame equilibrium $W_{1}^{*}, T(b)$, the stage III subgame equilibrium never involves foreclosure by b1. The subgame equilibrium wholesale offer, prices and profits are:

$$
h_{1}=s_{1}=\frac{1}{2} v, s_{2}=\frac{2+3 \delta}{4+4 \delta} v\left(>s_{1}\right), \pi_{b 1}=\frac{1}{4}\left(\beta_{1}+\frac{2+\delta}{2+2 \delta} \beta_{2}\right) v^{2}-b(T), \pi_{b 2}=\frac{\delta}{16+16 \delta} \beta_{2} v^{2} .
$$

\footnotetext{
${ }^{20}$ Without the pure performance based rule, strategic manipulation of league competitive balance by broadcasters would enter the picture. This may be an interesting topic for study, but is left aside here.

${ }^{21}$ Asterisks will be used to indicate laissez-faire SPE values of variables.
} 
Some elaboration is useful. First note that, from (2.5)-(2.8), b2 profits are;

$$
\begin{aligned}
& \pi_{b 2}\left(s_{2}, s_{1}, v, h_{1}\right)=\left(s_{2}-h_{1}\right)\left(\beta_{2}+\frac{1}{1+\delta} \beta_{1}\right)\left(v-s_{2}\right) \text { if } 0 \leq s_{2} \leq(1+\delta) s_{1}-\delta v \\
& \pi_{b 2}\left(s_{2}, s_{1}, v, h_{1}\right)=\left(s_{2}-h_{1}\right)\left[\beta_{2}\left(v-s_{2}\right)+\frac{1}{\delta} \beta_{1}\left(s_{1}-s_{2}\right)\right] \text { if }(1+\delta) s_{1}-\delta v<s_{2} \leq s_{1} \\
& \pi_{b 2}\left(s_{2}, s_{1}, v, h_{1}\right)=\left(s_{2}-h_{1}\right) \beta_{2}\left[\left(v-s_{2}\right)-\frac{1}{\delta}\left(s_{2}-s_{1}\right)\right] \text { if } s_{1} \leq s_{2}<\frac{1}{1+\delta} s_{1}+\frac{\delta}{1+\delta} v \\
& \pi_{b 2}\left(s_{2}, s_{1}, v, h_{1}\right)=0 \text { if } \frac{1}{1+\delta} s_{1}+\frac{\delta}{1+\delta} v \leq s_{2}
\end{aligned}
$$

$\pi_{b 2}$ is a continuous, piecewise concave function of $s_{2}$, differentiable and concave within each separate domain of (3.4)-(3.7). If a piece has a stationary point within its domain then $\pi_{b 2}$ has a local maximum on that domain, and if the stationary point is to the right (left) of the domain then $\pi_{b 2}$ is increasing (decreasing) on that domain. Identifying when stationary points are within domain allows the global maximum of $\pi_{b 2}$ to be found, as follows (see appendix for the full argument). It turns out that if $\left(s_{1}, h_{1}\right)$ is in region $\mathrm{A}$ in Figure 1 (where $a \equiv \frac{1+2 \delta}{2+2 \delta} v$ ), then b2's best response is at the stationary point of (3.4), with $s_{2}=\frac{1}{2} v+\frac{1}{2} h_{1}<s_{1}$. Here b1

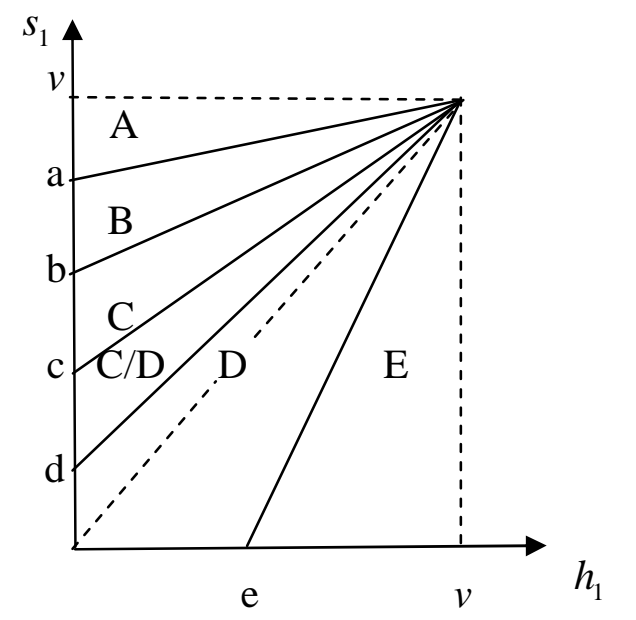

Figure 1: stage III laissez-faire regions

would be offering such a high retail price that it would get no demand - self-foreclosure from the retail market, with b1 reliant on wholesale income. For $\left(s_{1}, h_{1}\right)$ in region B $\left(b \equiv \frac{\delta\left(2 \delta \beta_{2}+2 \beta_{1}+\beta_{2}\right)}{\beta_{1}+\delta\left(2 \delta \beta_{2}+2 \beta_{1}+2 \beta_{2}\right)} v\right)$ the best response is at a kink in the $\mathrm{b} 2$ profit function, on the border between the (3.4) and (3.5) domains; $s_{2}=(1+\delta) s_{1}-\delta v<s_{1}$. Again b1 gets no retail market. In region $\mathrm{C}\left(c=\frac{\delta}{1+2 \delta} v\right)$, the best response is at the stationary point of (3.5), $s_{2}=\frac{\delta \beta_{2}}{2 \delta \beta_{2}+2 \beta_{1}} v+\frac{\beta_{1}}{2 \delta \beta_{2}+2 \beta_{1}} s_{1}+\frac{1}{2} h_{1}<s_{1}$, and in $\mathrm{D}\left(d \equiv \frac{\delta \beta_{2}}{2 \delta \beta_{2}+\beta_{1}} v\right)$ the best response is at the stationary point of (3.6), $s_{2}=\frac{\delta}{2+2 \delta} v+\frac{1}{2+2 \delta} s_{1}+\frac{1}{2} h_{1}>s_{1}$. In C, b2 still offers the lower retail price, the reverse in $\mathrm{D}$; in $\mathrm{C}$ and $\mathrm{D}$ both $\mathrm{b} 1$ and $\mathrm{b} 2$ get positive market share and profits. Between regions $\mathrm{C}$ and $\mathrm{D}$ is the region labelled C/D. Here b2's profit function kinks up as $s_{2}$ increases from below to above $s_{1}$ - as b2 raises $s_{2}$ above $s_{1}$ it loses customers (type 2), but slowly compared to the rate at which it gains (type 1) customers if it lowers $s_{2}$, since $\beta_{1}>\beta_{2}$. The profit function then has 2 stationary points, one as described for $\mathrm{C}$ and one as for $\mathrm{D}$. The best response is that with the larger $\mathrm{b} 2$ profit (both if the profits are equal). On a subset of this C/D region there will be a "jump" in b2's best response, where it flips from offering the lower price (C) to the higher price (D). Finally in region $\mathrm{E}\left(e=\frac{\delta}{1+\delta} v\right), \mathrm{b} 2$ cannot make positive profit, and is effectively foreclosed. 
Given the $\mathrm{b} 2$ best responses, maximum $\mathrm{b} 1$ profit over region $\mathrm{E}$ is the maximum foreclosure profit (with $s_{1}=\frac{1}{2} v$ ). Unsurprisingly, this exceeds anything attainable under self-foreclosure (in A or B). But it is always less than the maximum over region $\mathrm{D}$, at $h_{1}=s_{1}=\frac{1}{2} v$, where both broadcasters are active and $s_{2}>s_{1}=h_{1}$; this ensures the impossibility of foreclosure, to be discussed further in Section 3.3. In fact the b1 profit maximum over D is its profit maximum over all regions, as stated in Lemma 2.

If $b 2$ is the right's winner, the difference is that the previous upward kink in the loser profits as it increased its prices from below to above that of the winner now becomes a downward kink, and the analogue of the region C/D now becomes a region where the loser has a unique maximum at a kink, like B earlier. However this makes no essential difference, and the outcome is exactly parallel to Lemma 2 - just interchange the subscripts 1 and 2 to give:

Lemma 3 Given that $\mathrm{b} 2$ won the rights paying $b$ at stage $\mathrm{I}$, and the resulting stage II subgame equilibrium $W_{1}^{*}, T(b)$, the stage III subgame equilibrium never involves foreclosure by b2. The subgame equilibrium wholesale offer, prices and profits are:

$$
h_{2}=s_{2}=\frac{1}{2} v, s_{1}=\frac{2+3 \delta}{4+4 \delta} v\left(>s_{2}\right), \pi_{b 2}=\frac{1}{4}\left(\beta_{2}+\frac{2+\delta}{2+2 \delta} \beta_{1}\right) v^{2}-b(T), \pi_{b 1}=\frac{\delta}{16+16 \delta} \beta_{1} v^{2} .
$$

Two further remarks are in order. First the laissez-faire stage III wholesale-retail margin for the right's winner is always $m_{1} \equiv s_{1}-h_{1}=0$. That it is not positive stems from our simplifying assumption that there are no channel production or transmission costs for b1 or b2. Secondly, the impossibility of foreclosure in Lemma $2 / 3$ is a more general result than reported. The next section elaborates on this.

\subsection{The impossibility of foreclosure; a more general result}

The context is now a more general 2 firm "Wholesale versus Foreclosure" Game, where the previous stage III subgame is a special case. Firm 1 (b1 or b2) possesses an indivisible essential input (sports channel) that allows it to produce a good at constant marginal cost $c_{1} \geq 0$, sold at retail price $s_{1}$. It can make a wholesale offer to firm 2 , whereby the input is also made available to firm 2, allowing it to produce an imperfect substitute good at some constant marginal cost $c_{2} \in\left[0, c_{1}\right]$ which it then sells retail at price $s_{2}$, paying firm 1 an amount $h_{1}$ per unit sold; $c_{2}>c_{1}$ is discussed later. If firm 1 does make a wholesale offer, it announces $h_{1}$ and $s_{1}$, after which firm 2 chooses $s_{2}$. Demand functions for the 2 goods are $Q_{i}\left(s_{1}, s_{2}\right), i=1,2$, the number of consumers each buying 1 unit of $\operatorname{good} i$ at prices $s_{1}, s_{2}$; $Q\left(s_{1}, s_{2}\right)=Q_{1}\left(s_{1}, s_{2}\right)+Q_{2}\left(s_{1}, s_{2}\right)$ is total market demand. Alternatively to the wholesale offer, firm 1 may foreclose, in which case only good 1 is available with demand function $Q_{1 f}\left(s_{1}\right)$. Assumptions on demand functions are;

(A1) $Q_{i}: \mathfrak{R}_{+}^{2} \rightarrow \mathfrak{R}_{+}, i=1,2$ are continuous functions.

(A2) There exists $v>c_{1}$ such that $Q_{1}\left(s_{1}, s_{2}\right)=0$ for all $s_{2} \geq 0, s_{1} \geq v$, and $Q_{2}\left(s_{1}, s_{2}\right)=0$ for all $s_{1} \geq 0, s_{2} \geq v$.

So $v$ is an absolute upper bound on both prices, beyond which demand is 0 .

(A3) $Q_{1 f}\left(s_{1}\right)=Q_{1}\left(s_{1}, s_{2}\right)$ for any $s_{2}$ where $Q_{2}\left(s_{1}, s_{2}\right)=0$.

Here $Q_{1}\left(s_{1}, s_{2}\right)$ is the demand for good 1 when its price is $s_{1}$ and it is the only good sold in the market, defining $Q_{1 f}\left(s_{1}\right)$. 
(A4) $Q_{1 f}\left(c_{1}\right)>0$.

This is to ensure a positive profit solution to firm 1's foreclosure pricing problem.

(A5) For $s \in \Re_{+}$where $Q_{2}(s, s)>0$, raising $s_{2}$ from $s$ ( $s_{1}$ fixed at $s$ ) strictly reduces $Q_{2}$ and $Q$, with $Q_{2}$ reaching 0 at some finite (choke) price $\bar{s}_{2}(s)>s$; lowering $s_{2}$ from $s$ ( $s_{1}$ fixed at $s$ ) strictly increases $Q_{2}$ and $Q$.

This is a minimal assumption on "downward sloping demand" for good 2; the assumption on total demand is satisfied in our broadcaster model - violated only if the goods were perfect substitutes $(\delta=0)$.

(A6) There exists $\lambda>0$ such that $Q_{2}(s, s) \geq \lambda Q_{1}(s, s)$ for all $s \in \Re_{+}$.

This holds if the market for good 2 is "bigger" in that $Q_{2}(s, s) \geq Q_{1}(s, s)$ for all $s \in \mathfrak{R}_{+}$. It also holds when good 2 has the smaller market, provided it does not vanish before that of good 1 . The import of (A5) is that $Q_{1}(s, s)=0$ if $Q_{2}(s, s)=0$. It certainly holds in the earlier model where $D_{b 2}(s, s)=\frac{\beta_{2}}{\beta_{1}} D_{b 1}(s, s)\left(=\beta_{2}(v-s)\right)$.

After foreclosure, payoffs are $\Pi_{1}=\left(s_{1}-c_{1}\right) Q_{1 f}\left(s_{1}\right), \Pi_{2}=0$ and, with wholesaling, $\Pi_{1}=\left(s_{1}-c_{1}\right) Q_{1}\left(s_{1}, s_{2}\right)+h_{1} Q_{2}\left(s_{1}, s_{2}\right), \Pi_{2}=\left(s_{2}-c_{2}-h_{1}\right) Q_{2}\left(s_{1}, s_{2}\right)$. Generally for any such Game (which include any of the previous stage III broadcaster subgames where $c_{1}=c_{2}=0$ ) we have:

Proposition 1 Under (A1)-(A6) there exists a subgame perfect equilibrium for the Wholesale versus Foreclosure Game; foreclosure never occurs in any equilibrium.

In particular if the 2 firms are symmetric both in marginal costs $\left(c_{1}=c_{2}\right)$ and demands $\left(Q_{1}(s, s)=Q_{2}(s, s)\right)$ then foreclosure will never happen provided the minimal demand assumptions (A1)-(A5) hold; moreover, the same is true if the downstream firm 2 has lower costs and bigger demand. In fact the downstream firm can face a higher marginal cost, to an extent, and still Proposition 1 holds;

Corollary to Proposition 1 There exists $\varepsilon^{*}>0$ such that if $c_{2}=c_{1}+\varepsilon, \varepsilon \in\left(0, \varepsilon^{*}\right)$ then Proposition 1 continues to hold

The reasons for the foreclosure impossibility are simply seen if $c_{1}=c_{2} \equiv c$. Let $s_{1}^{*}$ be an optimal foreclosure price for firm 1. Consider the wholesale offer $h_{1}=s_{1}^{*}-c_{1}$ with $s_{1}=s_{1}^{*}$. Then firm 1 gets the same return per unit it sells wholesale as retail. If firm 2 responded to the offer by matching $s_{2}=s_{1}^{*}$, firm 2 would get positive market share (here (A6) is essential), but 0 profit. If firm 2 responded with the higher choke price $\bar{s}_{2}\left(s_{1}{ }^{*}\right)$ it would again get 0 profit whilst firm 1 would earn the foreclosure profit. Firm 2 will choose between these extremes (ensuring positive profit), and from (A5) total demand exceeds foreclosure level, as will firm 1 's profit. Thus there is always a wholesale offer that beats foreclosure for firm 1. Proposition 1 and the Corollary show that this reasoning survives asymmetric marginal costs, as stated. The proofs show that firm 2 makes strictly positive profits in SPE. Firm 2 could be reinterpreted as a retail-only new entrant facing fixed entry cost of $f$ say. Then, there exists $f^{*}>0$ such that Proposition 1 and the Corollary also hold if $f \in\left(0, f^{*}\right)$; the entrant would be accommodated rather than deterred. 
Perhaps the most surprising feature of Proposition 1 is that the foreclosure impossibility survives even if retail market competition is fierce - arbitrarily close to perfect competition. Provided the retailed goods are imperfect substitutes to some degree, the owner of the essential facility will always find a wholesale offer that provides enough wholesale revenue to compensate any loss of retail market share. It is this feature that seems to distinguish Proposition 1 from a large prior literature, in particular Proposition 2 in the closest antecedent, Harbord and Ottaviani (2001), where restrictions on its Hotelling transport cost parameter are used for their foreclosure impossibility result ${ }^{22}$.

The main lesson from this section for the sports league/broadcaster model, is that the crucial assumption generating the laissez-faire foreclosure impossibility in Lemmas 2 and 3 is that $v$ is the same for both consumer types, as it is this which ensures (A6); we argued earlier however that this assumption seems entirely natural in the context we have in mind.

\subsection{The auction outcome}

Consider FPSB. To unencumber notation we normalise $d_{b}\left(W_{1}^{*}\right)=1$ throughout, so that $v^{2}=4 T^{\sigma}$. Then Lemmas 2 and 3 provide the formulae for payoffs in the reduced form stage I Game whose Nash equilibria will complete the SPE; subscript $i W$ indicates bi has won the rights, $i L$ otherwise. This is a simultaneous move Game with the broadcasters as the 2 Players, with strategies $b_{1}, b_{2} \geq 0$, and with payoffs;

(a) If $b=b_{1} \geq b_{2}$ (so b1 wins the rights) and $T \geq T_{\min }$ is defined by $b=T^{\frac{1+\varepsilon}{\varepsilon}}-A T^{\sigma}$;

$$
\begin{aligned}
& \pi_{1 W}(T) \equiv\left(\alpha+\beta_{1}+\frac{2+\delta}{2+2 \delta} \beta_{2}\right) T^{\sigma}-T^{\frac{1+\varepsilon}{\varepsilon}} \\
& \pi_{2 L}(T) \equiv \frac{\delta}{4+4 \delta} \beta_{2} T^{\sigma}
\end{aligned}
$$

(b) If $b=b_{2}>b_{1}$ (so b2 wins the rights) and $T \geq T_{\min }$ is defined by $b=T^{\frac{1+\varepsilon}{\varepsilon}}-A T^{\sigma}$;

$$
\begin{aligned}
& \pi_{1 L}(T) \equiv \frac{\delta}{4+4 \delta} \beta_{1} T^{\sigma} \\
& \pi_{2 W}(T) \equiv\left(\alpha+\beta_{2}+\frac{2+\delta}{2+2 \delta} \beta_{1}\right) T^{\sigma}-T^{\frac{1+\varepsilon}{\varepsilon}}
\end{aligned}
$$

Defining $\eta \equiv \frac{\varepsilon \sigma}{1+\varepsilon} \in(0,1)$, each $\pi_{i W}(T)$ is strictly concave with global maxima at $\hat{T}_{i}$;

$$
\begin{aligned}
& \hat{T}_{1}=\left[\eta\left(\alpha+\beta_{1}+\frac{2+\delta}{2+2 \delta} \beta_{2}\right)\right]^{\frac{\varepsilon}{1+\varepsilon-\varepsilon \sigma}} \\
& \hat{T}_{2}=\left[\eta\left(\alpha+\beta_{2}+\frac{2+\delta}{2+2 \delta} \beta_{1}\right)\right]^{\frac{\varepsilon}{1+\varepsilon-\varepsilon \sigma}}
\end{aligned}
$$

When positive, $b\left(\hat{T}_{i}\right)$ is the bid that would be made by broadcaster $i$ if it were the sole bidder for the rights - although it would secure the rights with a lower bid, it would raise to $b\left(\hat{T}_{i}\right)$ to enhance the resulting league and channel quality, indicating an externality from the size of the bid on the bidder, via club decisions. $b\left(\hat{T}_{i}\right)$ will be referred to as the optimal standalone bid for broadcaster $i$. Notice that each $\hat{T}_{i}$ is increasing in both pay-TV market size parameters

\footnotetext{
${ }^{22}$ More recently Borreau et al. (2011, section V(ii)) (see also Hoffler and Schmidt (2008), Ordover and Shaffer (2007)), have results on foreclosure of a downstream entrant when there are 2 integrated suppliers of the essential input; sufficient lack of substitutability between the (3) retail differentiated products is needed for foreclosure impossibility. Formally, Hombert et al. (2009, p.27) have the closest result to our Proposition 1 that we have found, but based on the less primitive demand assumption that, in our notation, $Q_{2}\left(s_{1}^{*}, s_{1}^{*}+c_{2}-c_{1}\right)>0$ where $s_{1}^{*}$ is an optimal foreclosure price for firm 1 .
} 
( $\beta_{1}$ and $\beta_{2}$ ), naturally since increases in these parameters increase marginal retail or wholesale revenue from bid increases with no change in marginal cost. And the positive impact of increases in $\alpha$ is similarly intuitive, reducing marginal bid cost. Increases in $\delta$ reduce pay-TV market competition, and because of the positive impact on marginal wholesale revenue increase $\hat{T}_{i}$.

Each $\pi_{i L}(T)$ is globally increasing, indicating increased profit from wholesale purchase of a higher quality sports channel, and a second auction externality. Define $\tilde{T}_{i}$ as the largest $T$ value that makes $\pi_{i W}(T) \geq \pi_{i L}(T)$. This is the strictly positive value of $T$ that equates $\pi_{i W}(T)$ to $\pi_{i L}(T)$ in (3.8),(3.10)/(3.9),(3.11), namely; ${ }^{23}$

$$
\begin{aligned}
& \tilde{T}_{1}=\left(\alpha+\frac{4+3 \delta}{4+4 \delta} \beta_{1}+\frac{2+\delta}{2+2 \delta} \beta_{2}\right)^{\frac{\varepsilon}{1+\varepsilon-\varepsilon \sigma}} \\
& \tilde{T}_{2}=\left(\alpha+\frac{4+3 \delta}{4+4 \delta} \beta_{2}+\frac{2+\delta}{2+2 \delta} \beta_{1}\right)^{\frac{\varepsilon}{1+\varepsilon-\varepsilon \sigma}}
\end{aligned}
$$

The interpretation is that bids $b \leq b\left(\tilde{T}_{i}\right)$ are the only winning bids with the property that broadcaster $i$ would prefer that it made this winning bid rather than the rival. $b\left(\tilde{T}_{i}\right)$ will be referred to as the largest bid to win for broadcaster $i$. As with $\hat{T}_{i}$, each $\tilde{T}_{i}$ increases with $\alpha, \beta_{1}$ and $\beta_{2}$, and decreases with $\delta$.

Always $\quad \hat{T}_{1}>\hat{T}_{2} \quad$ and $\quad \tilde{T}_{1}>\tilde{T}_{2} ; \quad \hat{T}_{1} \geq \tilde{T}_{1}>\tilde{T}_{2} \quad$ if $\quad \eta \geq Y \equiv \frac{(4+4 \delta) \alpha+(4+3 \delta) \beta_{1}+(4+2 \delta) \beta_{2}}{(4+4 \delta) \alpha+(4+4 \delta) \beta_{1}+(4+2 \delta) \beta_{2}}$ $\tilde{T}_{1}>\hat{T}_{1}>\tilde{T}_{2}$ if $Y>\eta>X \equiv \frac{(4+4 \delta) \alpha+(4+3 \delta) \beta_{2}+(4+2 \delta) \beta_{1}}{(4+4 \delta) \alpha+(4+4 \delta) \beta_{1}+(4+2 \delta) \beta_{2}} ;$ and $\tilde{T}_{1}>\tilde{T}_{2} \geq \hat{T}_{1}$ if $X \geq \eta$. For brevity, and given our policy objectives, we focus on equilibria where the large broadcaster wins the rights. Given this, the equilibria when $\eta>Y$ are ${ }^{24}$;

Proposition 2 Under laissez-faire with FPSB and with $\eta>Y$, the unique SPE league quality is $T^{*}=\hat{T}_{1}$, with bids $b_{1}^{*}=b\left(\hat{T}_{1}\right), b_{2}^{*} \leq b(Z)$ where $Z=\pi_{1 L}^{-1}\left[\pi_{1 W}\left(\hat{T}_{1}\right)\right]$; b1 wins the rights.

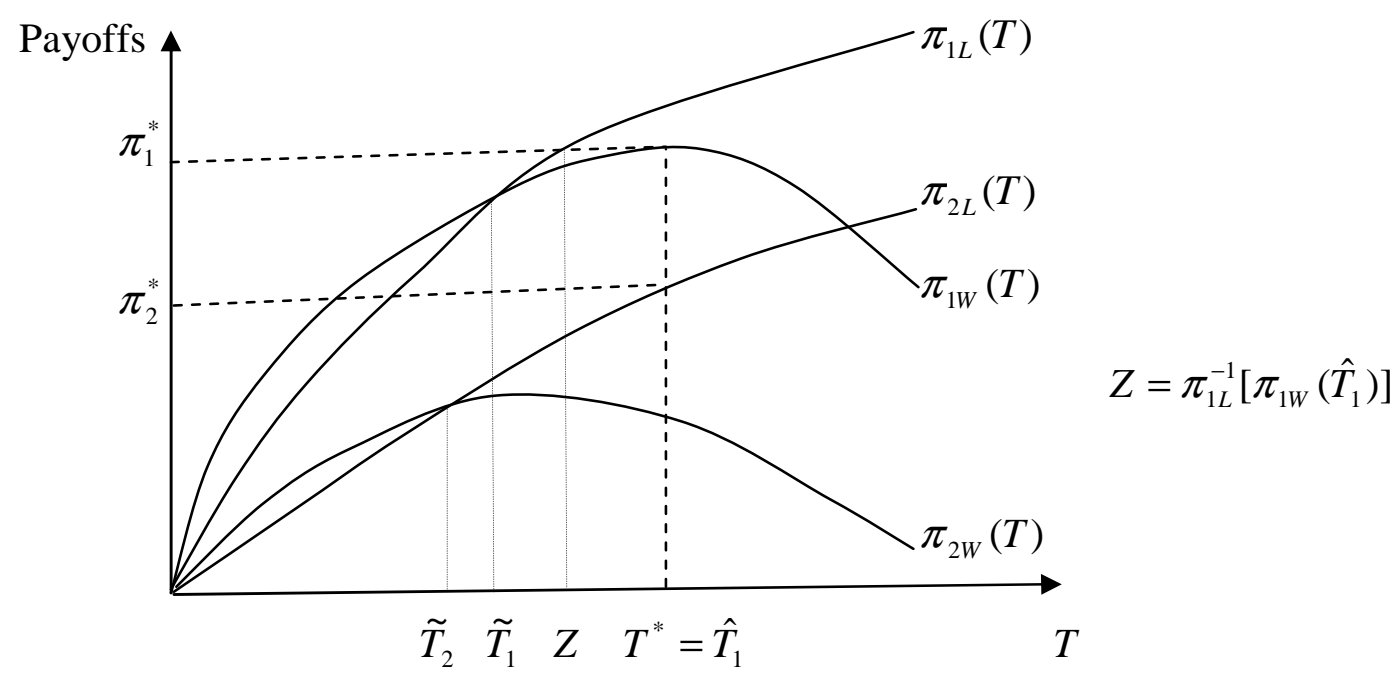

Figure 2; FPSB equilibrium for $\eta>Y$

\footnotetext{
${ }^{23}$ Note that $\tilde{T}_{2}>T_{\min }$, which will imply the irrelevance of the $T \geq T_{\min }$ domain restriction in following results.

${ }^{24}$ We note that equilibria similar to Proposition 1 but where b2 wins are possible on a subset of $\eta>Y$, although they cannot occur if $\eta$ is close to 1 . We ignore these equilibria for the reasons given.
} 
The winning bid, shown in Figure 2, is such that b1 would prefer to lose to b2 making a slightly higher bid. But b2 doesn't want to exceed the winning bid, and bids so low that b1 does not find it profitable to reduce its bid to a losing level. Instead, given b2's low bid, b1 bids higher with its optimal standalone bid, in pursuit of enhanced league and channel quality. Equilibria where the winning bid is the winner's optimal standalone bid, strictly higher than the rival bid, are quality-driven equilibria (QDE).

Parameters where $\eta \in(X, Y)$ give Proposition 3 and Figure 3;

Proposition 3 Under laissez-faire with FPSB and with $\eta \in(X, Y)$, there is a continuum of SPE levels of league quality, namely any $T^{*} \in\left[\hat{T}_{1}, \tilde{T}_{1}\right]$, with bids $b_{1}^{*}=b_{2}^{*}=b\left(T^{*}\right)$, plus, when $T^{*}=\hat{T}_{1}, b_{1}^{*}=b\left(T^{*}\right)>b_{2}^{*}$; b1 wins the rights.

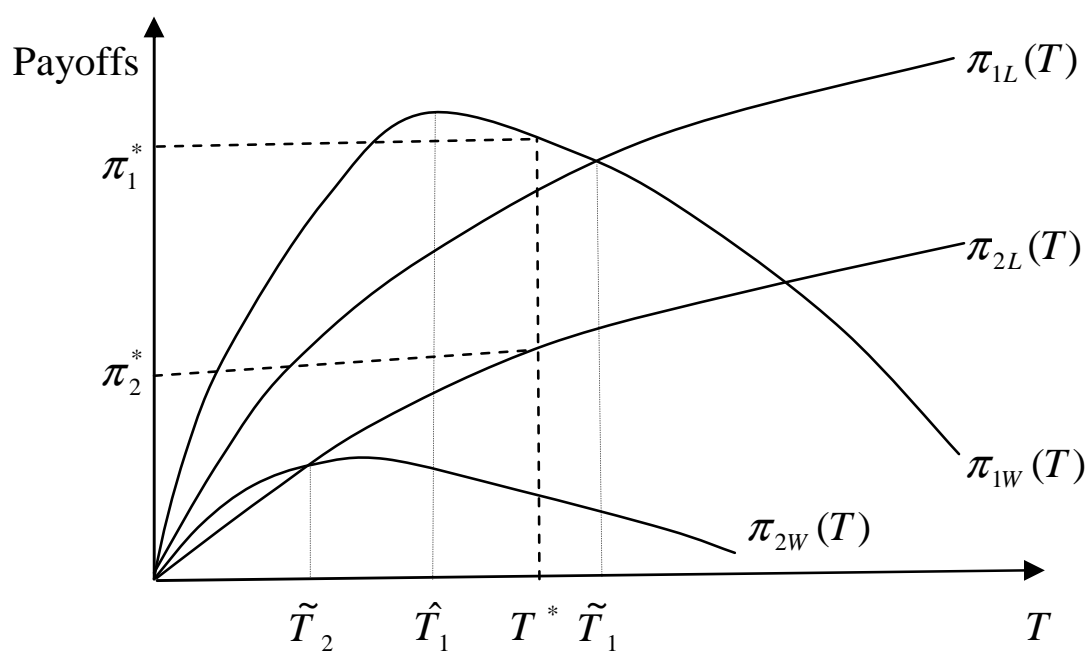

Figure 3; FPSB equilibrium for $\eta \in(X, Y)$

b1 always wins, and there are QDE, but now also a continuum of equilibria with equal bids strictly in excess of the optimal standalone bids, defining rival-driven equilibria (RDE). For $\eta<X$, Proposition 4 and Figure 4 emerge;

Proposition 4 Under laissez-faire with FPSB and with $\eta<X$, there is a continuum of SPE levels of league quality, namely any $T^{*} \in\left[\tilde{T}_{2}, \tilde{T}_{1}\right]$, with equal bids $b_{1}^{*}=b_{2}^{*}=b\left(T^{*}\right)$, and with b1 winning the rights.

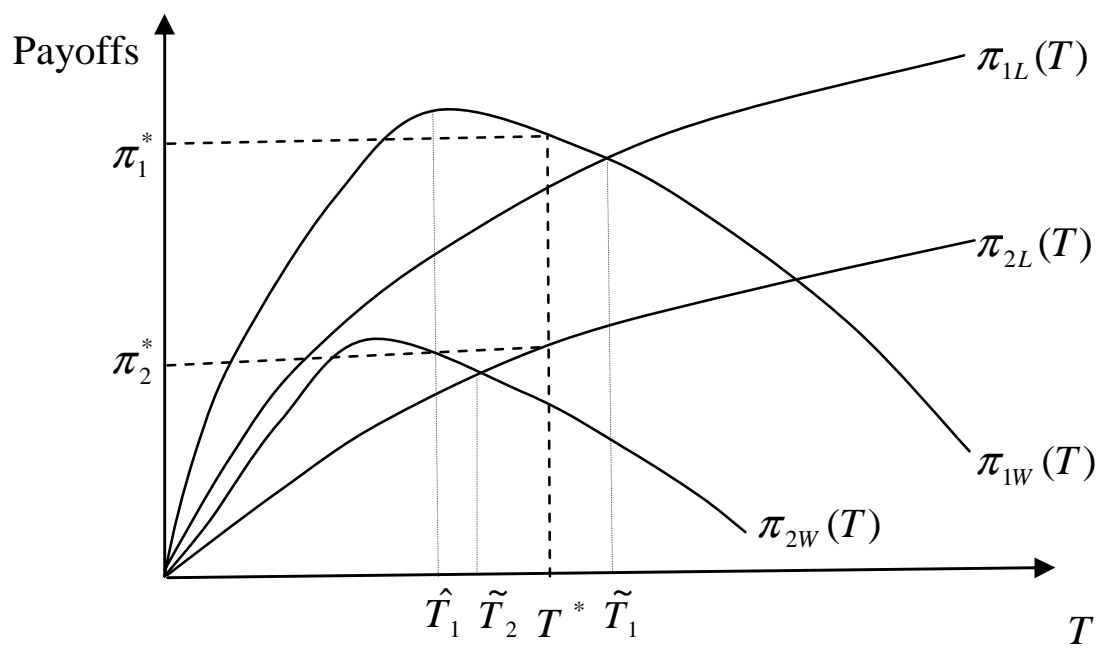

Figure 4; FPSB equilibrium for $\eta<X$ 
b1 again always wins, and there is just a continuum of RDE.

QDE cannot occur with SPSB - the lower bidder would benefit from a small increase in bid, raising equilibrium quality and profits from buying wholesale. The outcome at all parameters is the same as in Proposition 4;

Proposition 5 Under laissez-faire with SPSB and with any parameters, there is a continuum of SPE levels of league quality, namely any $T^{*} \in\left[\tilde{T}_{2}, \tilde{T}_{1}\right]$, with equal bids $b_{1}^{*}=b_{2}^{*}=b\left(T^{*}\right)$, and with b1 winning the rights.

Thus the set of equilibrium payments to the league (see Figures 2-4) are (weakly) smaller with SPSB than with FPSB - both the largest and smallest values are (weakly) smaller. In this sense, FPSB is better for the league.

Propositions 2-5 describe SPE rights bids and league quality. To complete the description of the SPE outcome, the corresponding win percentages are defined by $W_{1}^{*}$, stadium ticket prices by (3.2), and broadcaster prices and margin by Lemma 2;

$$
s_{1}^{*}=h_{1}^{*}=\left(T^{*}\right)^{\frac{1}{2} \sigma} ; s_{2}^{*}=\frac{2+3 \delta}{2+2 \delta}\left(T^{*}\right)^{\frac{1}{2} \sigma} ; m_{1}^{*}=0
$$

The results show a pure QDE regime when $\eta>Y$, a mixed QDE/RDE regime when $\eta \in(X, Y)$ and a pure RDE regime when $\eta<X$, with FPSB, and pure RDE at all parameters with SPSB. So QDE becomes more likely (with FPSB) if $\eta$ (or $\varepsilon, \sigma$ ) are large. The following derivative signs are easily checked, and indicate the effect of other parameters on the likelihood of QDE;

$$
\begin{gathered}
\partial X / \partial \beta_{1}, \partial Y / \partial \beta_{1}<0 ; \partial X / \partial \beta_{2}, \partial Y / \partial \beta_{2}>0 \\
\partial X / \partial \alpha, \partial Y / \partial \alpha>0 ; \partial X / \partial \delta, \partial Y / \partial \delta<0
\end{gathered}
$$

Thus, higher values of $\beta_{1}$ and $\delta$ (as well as $\varepsilon, \sigma$ ) favour QDE, whilst higher values for $\beta_{2}$ and $\alpha$ reduce the likelihood of QDE. Some intuition is as follows.

(i) For QDE b1 needs to bid in excess of the rival to enhance quality. The money it puts in leads clubs to increase player expenditure $(E)$, which increases player salaries $\left(w=E^{\frac{1}{1+\varepsilon}}\right)$ and league quality ( $T=E^{\frac{\varepsilon}{1+\varepsilon}}$ ), but if $\varepsilon$ is large the quality effect is large. The profitability to b1 of the increased quality is accentuated if the consumers' willingness-to-pay for quality $(\sigma)$ is high, or if b1's pay-TV market is large ( $\beta_{1}$ large). Thus large $\varepsilon, \sigma$ or $\beta_{1}$ all make b1's overbidding to create QDE more likely.

(ii) Increases in $\delta$ endow broadcasters with more retail market power, which leads to increased profits from losing, but reduced profits from winning - the winner's exclusive rights ownership means it gets more out of a more competitive pay-TV market. The 2 combine to force down largest bids to win more than the fall in optimal standalone bids, making QDE more likely with higher $\delta$.

(iii) The dominant impact of higher $\beta_{2}$ is to increase b2's largest bid to win, which makes QDE less likely, whilst higher $\alpha$ means that league quality would be high without any broadcast income, reducing the incentive for b1 to boost it further. 
Whilst information about EPL auctions is piecemeal, it is clear that 2003 and after fit FPSB better than $\mathrm{SPSB}^{25}$. In 2003, EU concerns led to the first packaging of games, 3-way, in the expectation that this would loosen Sky's previous $100 \%$ hold on rights. It didn't. Sky won all 3 packages, against zero rival bids for the best (gold and silver) packages, and with a large margin over rivals for bronze (see Harbord and Szymanski, 2004); perhaps QDE looks a better fit than RDE. In 2007 and 2010, the league, under further EU pressure, agreed that any 1 bidder could get at most 5 (of the now 6) packages; Setanta and ESPN did pick up lower value packages, with no real evidence of Sky facing close competition for the better packages, which it won. Only in 2013 did it emerge that Sky had been run close (by BT) at the top end of package quality, but it still retained the large majority of the rights. Perhaps regarding the last 4 auctions as QDE is credible ${ }^{26}$. If so, the increased size of winning bids $\left(\hat{T}_{1}\right)$ is consistent with our results, if 2003-13 was a period when $\alpha, \beta_{1}$ or $\beta_{2}$ increased, or $\delta$ decreased, with no significant reverse changes; this seems credible.

\section{THE IMPACT OF MARGIN REGULATION ON LEAGUE RIGHTS INCOME AND QUALITY}

Regulation is now imposed on the rights winner. At stage III, the winner must make a wholesale offer (foreclosure is not possible, although this is redundant), and the offer must (if bi has the rights) respect the constraint $m_{i}=s_{i}-h_{i} \geq m_{R}>0$, thus ensuring that the margin exceeds its laissez-faire 0 value. We look at the effect on league rights income and quality, and their welfare consequences, for both laissez-faire QDE and RDE equilibria. Results are local, describing the effects of $m_{R}$ just above 0 .

Some parts of the SPE analysis are common to RDE/QDE and some are unchanged from laissez-faire. With margin regulation, stage II win percentages and league quality are again described by $W_{1}^{*}$ and $T=T(b)$, with stadium ticket prices given by (3.2); any impact of regulation on league rights income and quality will therefore be in the same direction. Suppose b1 won the rights at stage I, paying $b(T)$. In the stage III subgame, b1 is restricted to choices of $\left(s_{1}, h_{1}\right)$ on or above the bold line in Figure 5. In region D (bounded by the lines with intercepts $d$ and e, as in Figure 1), b1's profit function (anticipating b2's best response) attained its unconstrained maximum at $h_{1}=s_{1}=\frac{1}{2} v$ (Lemma 2). Calculating the maximum of that profit function subject to the bold line constraint produces a b1 profit value below that of Lemma 2, converging to that value as $m_{R} \rightarrow 0$. Since the Lemma 2 value strictly exceeded anything attainable for $\mathrm{b} 1$ from choices in other regions under laissez-faire, and since the regulation can only reduce these alternatives, it follows that b1's bold line constrained region D maximum will provide the subgame equilibrium outcome for $m_{R}$ positive but sufficiently small; foreclosure remains an impossibility.

\footnotetext{
${ }^{25}$ We have no further information regarding 2000, but noted earlier (footnote 11) that SPSB might be more credible for the first 2 auctions, in which case RDE and close bids would be expected, as seems to have been the case (see again footnote 11 references).

${ }^{26}$ Whilst this is speculative, it is common knowledge that investment in quality is part of Sky's business strategy, acknowledged by Ofcom (2010, p.14,p.595). By 2010, at least one influential commentator seemed convinced of QDE in the then recent auctions; "The money it [Sky] pours in is no longer dictated by what it must pay to outbid its rivals but what it feels must be invested to maintain the quality. In other words, it pours billions into Premier League football in order that clubs can continue to compete for the best players in a global market" (Owen Gibson, The Guardian, 26 March 2010).
} 
This provides the content of part (a) of Lemma 4 and (b) is analogous for the case where b2 won at stage I:

Lemma 4 (a) Given that b1 won the rights paying $b$ at stage I, given the resulting stage II subgame equilibrium $W_{1}^{*}, T(b)$, and given $m_{R}>0$ but sufficiently small, the stage III subgame equilibrium never involves foreclosure by b1. The subgame equilibrium wholesale offer, prices and profits are:

$$
\begin{gathered}
s_{1}=\frac{1}{2} v+\frac{\beta_{2}(1+\delta)}{2 \beta_{1}(1+\delta)+\beta_{2}(2+\delta)} m_{R}, \quad h_{1}=\frac{1}{2} v-\frac{2 \beta_{1}(1+\delta)+\beta_{2}}{2 \beta_{1}(1+\delta)+\beta_{2}(2+\delta)} m_{R}, s_{2}=\frac{2+3 \delta}{4+4 \delta} v-\frac{\beta_{1}(1+\delta)}{2 \beta_{1}(1+\delta)+\beta_{2}(2+\delta)} m_{R} \\
\pi_{b 1}=\frac{2 \beta_{1}(1+\delta)+\beta_{2}(2+\delta)}{8+8 \delta} v^{2}-b(T)-\frac{1+\delta}{\delta} \frac{\beta_{1}(1+\delta)+\beta_{2}}{2 \beta_{1}(1+\delta)+\beta_{2}(2+\delta)} \beta_{2} m_{R}^{2} \\
\pi_{b 2}=\frac{\delta}{4+4 \delta} \beta_{2}\left[\frac{1}{2} v+\frac{(1+\delta)^{2}}{\delta} \frac{2 \beta_{1}+\beta_{2}}{2 \beta_{1}(1+\delta)+\beta_{2}(2+\delta)} m_{R}\right]^{2}
\end{gathered}
$$

(b) Given that $\mathrm{b} 2$ won the rights paying $b$ at stage I, given the resulting stage II subgame equilibrium $W_{1}^{*}, T(b)$, and given $m_{R}>0$ but sufficiently small, the stage III subgame equilibrium never involves foreclosure by b2. The subgame equilibrium wholesale offer, prices and profits are:

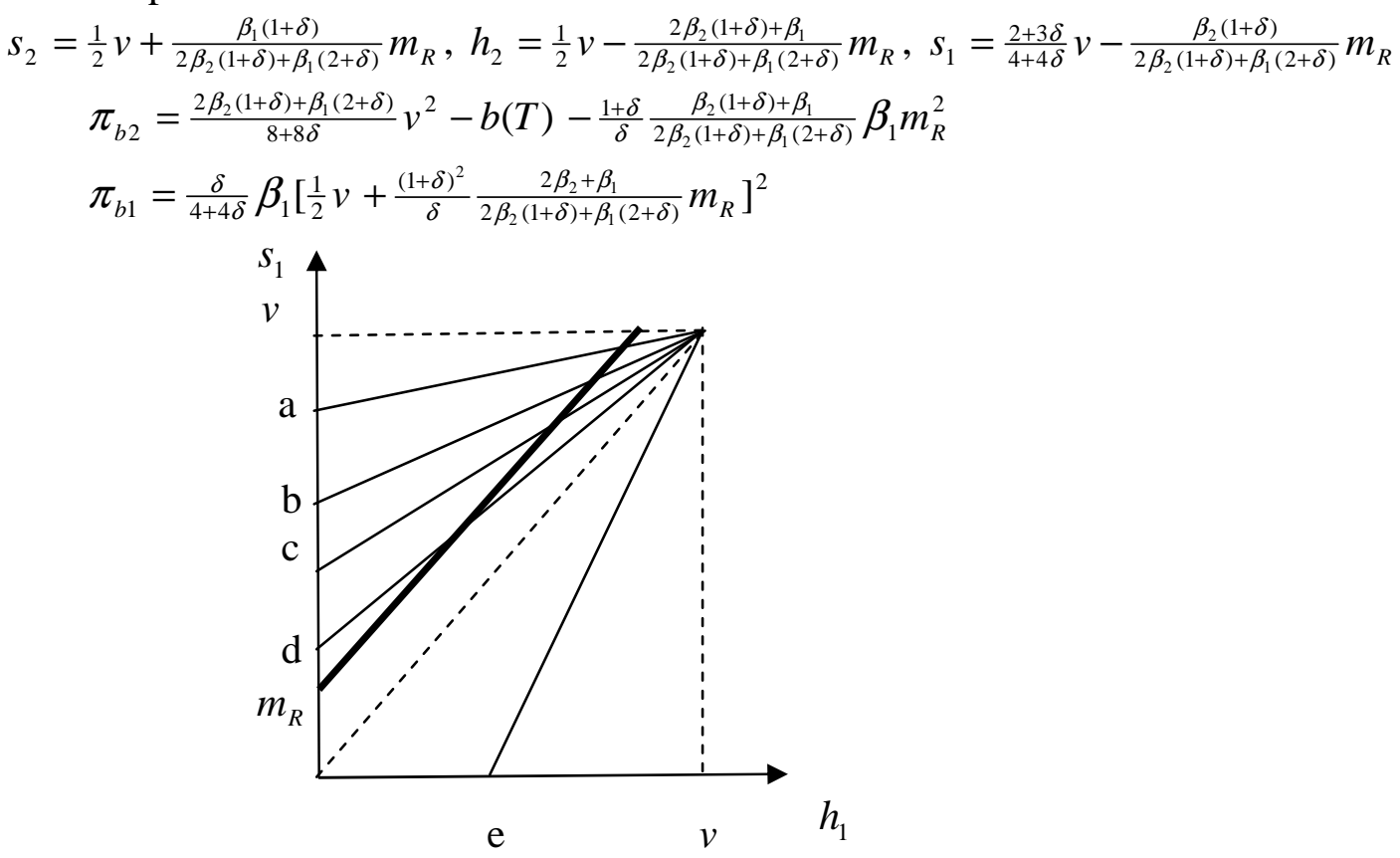

Figure 5: stage III margin regulation regions

Under FPSB, stage I reduced form payoffs in (3.8)-(3.11) become;

$$
\begin{aligned}
& \pi_{1 W}\left(T, m_{R}\right)=\pi_{1 W}(T)-\frac{1+\delta}{\delta} \frac{\beta_{1}(1+\delta)+\beta_{2}}{2 \beta_{1}(1+\delta)+\beta_{2}(2+\delta)} \beta_{2} m_{R}^{2} \\
& \pi_{2 L}\left(T, m_{R}\right)=\frac{\delta}{4+4 \delta} \beta_{2}\left[T^{\sigma}+\frac{(1+\delta)^{2}}{\delta} \frac{2 \beta_{1}+\beta_{2}}{2 \beta_{1}(1+\delta)+\beta_{2}(2+\delta)} m_{R}\right]^{2} \\
& \pi_{1 L}\left(T, m_{R}\right)=\frac{\delta}{4+4 \delta} \beta_{1}\left[T^{\sigma}+\frac{(1+\delta)^{2}}{\delta} \frac{2 \beta_{2}+\beta_{1}}{2 \beta_{2}(1+\delta)+\beta_{1}(2+\delta)} m_{R}\right]^{2} \\
& \pi_{2 W}\left(T, m_{R}\right)=\pi_{2 W}(T)-\frac{1+\delta}{\delta} \frac{\beta_{2}(1+\delta)+\beta_{1}}{2 \beta_{2}(1+\delta)+\beta_{1}(2+\delta)} \beta_{1} m_{R}^{2}
\end{aligned}
$$

Immediately one sees in (4.1) and (4.4) that the effect of the regulation is to reduce the right's winner's profits by the same amount for all $T$ (and so for all winning bids). The optimal standalone bid is unaffected; with obvious notation, $\hat{T}_{i}\left(m_{R}\right)=\hat{T}_{i}, i=1,2$. On the other hand the regulation always leads to a decrease in the wholesale price offer by the winner (see $h_{1}, h_{2}$ formulae in Lemma 4), and so increases loser payoffs in (4.2) and (4.3). Coupled with 
the fall in winner profits, this ensures that regulation always reduces the largest bids to win of b1 and b2; $\tilde{T}_{i}\left(m_{R}\right)<\tilde{T}_{i}, i=1,2$.

It is straightforward to apply the reasoning of Propositions 2-5 to show;

Proposition 6 After the imposition of a sufficiently small positive $m_{R}$, and again restricting attention to equilibria where b1 wins, the set of equilibrium league qualities $T$, with winning bids $b(T)$, is:

(a) $\hat{T}_{1}$ if $\eta>Y$, $\left[\hat{T}_{1}, \tilde{T}_{2}\left(m_{R}\right)\right]$ if $\eta \in(X, Y)$, and $\left[\tilde{T}_{2}\left(m_{R}\right), \tilde{T}_{1}\left(m_{R}\right)\right]$ if $\eta<X$, when the auction is FPSB;

(b) $\left[\tilde{T}_{2}\left(m_{R}\right), \tilde{T}_{1}\left(m_{R}\right)\right]$ for all $\eta \in(0,1)$, when the auction is SPSB.

Consider FPSB. The regulation has no effect on rights income/quality in the pure QDE laissez-faire regime, and in all other regimes the rights income/quality weakly decline in the sense that neither end of the equilibrium intervals increases, and at least one declines; in the pure RDE laissez-faire regime, both ends decline. It is also informative to note that if one goes to the limit where $\beta_{1}=\beta_{2}$ (which means the auction tie-break is now decided on a coin toss), all reasoning carries through with the conclusions that $X=Y$, that $\eta>X=Y$ produces a unique QDE laissez-faire rights income/quality which is unaffected by regulation (locally), and that $\eta<X=Y$ produces a unique RDE laissez-faire rights income/quality which is reduced by the regulation. The conclusion that margin regulation has an adverse affect on rights income/quality in RDE seems reasonable. Thus, in the next section, a selection from the RDE continuum will be assumed to have the property that the equilibrium $T$ (or $v$ ) decreases as $m_{R}$ increases. And the same will be assumed for SPSB, where RDE is universal. Before that it is useful to note a quite general "duality" that sheds light on the impact of regulation in QDE, as follows.

In Lemma 4(a), continuing to assume b1 wins the rights, $\pi_{b 1}$ reduces to a function of $T$ (with $v^{2}=4 T^{\sigma}$ ) and $m_{R}$. Generally let us denote this function simply by $\pi(T, m)$. In the QDE regime the backwards induction that produces laissez-faire SPE implies that this SPE corresponds to the global unconstrained maximum of $\pi(T, m)$ over $T, m$; denote it $\left(T^{*}, m^{*}\right)$ and use subscripts to denote partial derivatives ( $\pi_{T}$ for $\partial \pi / \partial T$, and so on). If $m$ is fixed, the constrained maximum is defined by $\pi_{T}(T, m)=0$ which defines a function $T(m)$ whose derivative at the laissez-faire equilibrium (from the implicit function theorem) is $T^{\prime}\left(m^{*}\right)=-\pi_{T m}\left(T^{*}, m^{*}\right) / \pi_{T T}\left(T^{*}, m^{*}\right)$, which has the sign of $\pi_{T m}\left(T^{*}, m^{*}\right)$, assuming $\pi(T, m)$ is strictly concave in $T$. On the other hand, if instead $T$ is fixed, the parallel argument produces a function $m(T)$ with derivative $m^{\prime}\left(T^{*}\right)=-\pi_{m T}\left(T^{*}, m^{*}\right) / \pi_{m m}\left(T^{*}, m^{*}\right)$. It follows that $T^{\prime}\left(m^{*}\right)$ has the same sign as $m^{\prime}\left(T^{*}\right)$, assuming $\pi(T, m)$ is strictly concave in $m$ also, and this is a quite general "duality". But in QDE, $T^{\prime}\left(m^{*}\right)$ tells us the sign of the change in SPE league quality as margin regulation is imposed, and $m^{\prime}\left(T^{*}\right)$ tells us the sign of how b1's laissez-faire stage III margin changes with $T$. Thus the reason why margin regulation has no effect on $T$ in QDE in Proposition 6 is that changes in $T$ have no effect on b1's laissez-faire margin (always 0 ). In a previous version with somewhat different pay-TV demands, the laissez-faire margin increased with $T$, so margin regulation led to an increase in $T$, but changing elasticities in that specification produced an example where all was reversed 
and margin regulation decreased $T$. We conclude that the effect of margin regulation on $T$ is sensitive to the nature of pay-TV demands, and is not likely to be something that a regulator could rely on.

\section{THE WELFARE CONSEQUENCES OF MARGIN REGULATION}

We consider the consequences of margin regulation for the welfare of the interested parties, with the usual regulator primary focus on consumer surplus. The impact on stadium consumers is immediate - their surplus changes in the same direction as the rights income/quality. Suppose this falls (as suggested in RDE); then $c_{i}$ falls because of the decrease in league quality (bad for the consumers) but so does the ticket price $p_{i}$ (good, ceteris paribus - see (3.2)). However, the ticket price fall is only half the fall in $c_{i}$, stadium consumers are worse off, and their aggregate surplus goes down. If the rights income/quality is unchanged (QDE) then so are $c_{i}$ and $p_{i}$, and the surplus.

In laissez-faire equilibrium $s_{2}>s_{1}$ and some type 2 pay-TV consumers buy from b1, leading to the following expression for aggregate pay-TV consumer surplus:

$$
C S_{b}\left(s_{1}, s_{2}, v\right)=\frac{1}{2} \beta_{1}\left(v-s_{1}\right)^{2}+\frac{1}{2} \beta_{2}\left(v-s_{2}\right)^{2}+\frac{1}{2 \delta} \beta_{2}\left(s_{2}-s_{1}\right)^{2}
$$

This will remain the relevant formula after the introduction of a small positive $m_{R}$, which will cause perhaps a change in $v$ to $v\left(m_{R}\right)$ say and changes in $s_{1}$ and $s_{2}$ in line with Lemma 4(a). Treating $v\left(m_{R}\right)$ as a differentiable function leads to the following formula for $d C S_{b} / d m_{R}$ evaluated at $m_{R}=0$ :

$\underline{\text { Lemma } 5}$ For some positive numbers $K$ and $L, d C S_{b} / d m_{R}=K v^{\prime}(0)-L$.

Thus the effect of margin regulation on aggregate pay-TV consumer surplus decomposes into a quality effect $\left(K v^{\prime}(0)\right)$ and a price effect $(-L)$. The price effect is always negative. What happens is that in laissez-faire there are type 1 consumers who buy from b1, type 2 consumers who also buy from b1, and type 2 consumers who buy from b2 at its higher price. The regulation increases $s_{1}$ making the first 2 groups worse off, $s_{2}$ falls making the last group better off, but the aggregate effect is negative, dominated by the first 2 groups. In QDE, margin regulation has no effect on the league rights income and quality, $v^{\prime}(0)=0$ and there is no quality effect at all; aggregate pay-TV consumer surplus falls. For RDE an appropriate differentiable selection from the continuum would have $v^{\prime}(0)<0$, or this would follow without selection if $\beta_{1}=\beta_{2}$, as discussed in the previous section. Either way the fall in league rights income and quality reinforces the negative price effect with a negative quality effect; for sure aggregate pay-TV consumer surplus falls again. Margin regulation never provides a positive outcome for consumers.

Like stadium consumers the welfare of players and club owners moves in the same direction as the rights income/quality. If this falls (RDE), aggregate talent employed in the league falls and we move down the talent supply curve with lower $w$ and lower player salaries; also, since competitive balance is unaffected, the quality of both teams falls, and club owners are worse off. And if the rights income/quality is unchanged (QDE), players and owners are unaffected by margin regulation. At its worst (RDE), margin regulation makes all stadium and pay-TV 
consumers, club owners and players strictly worse off, and at its best (QDE) this strict Pareto disimprovement remains but weakly. The only potential benefits are, perversely, for the broadcasters themselves, which may happen.

In the QDE regime, and as remarked earlier, the impact of margin regulation is to reduce the profit for the right's winner (b1); the laissez-faire equilibrium corresponds to an unconstrained profit maximum for b1, and regulation merely imposes a constraint on this. However the regulation (see Lemma 4(a)) reduces the wholesale price offer from b1, and b2 is definitely better off. In RDE, things are perhaps surprisingly different for b1. Now the regulation actually increases b1's profit. The reasons are that the upward pressure on b1's winning bid exerted (in laissez-faire RDE) by b2 is now reduced (b2's largest bid to win falls) allowing b1 to win with a reduced bid, which is decisive in generating a profit increase ${ }^{27}$ for b1. The effect of regulation on b2 in RDE is ambiguous. The lower league quality that follows the lower winning bid is, ceteris paribus, a bad thing for b2; but the downward pressure on the wholesale price may partially or fully offset this.

\section{WHOLESALE PRICE REGULATION}

In this section we discuss an alternative form of regulation, i.e. wholesale price regulation, and compare it to our previous analysis of the margin regulation ${ }^{28}$. The constraint on $b 1$ is now a direct downward regulation on the wholesale price; $h_{1} \leq h_{R}<h_{1}^{*}$. We omit details, and focus on the differences from margin regulation. With respect to the stage III subgame, the main difference is that the imposition of local $\left(h_{R}\right.$ near $\left.h_{1}^{*}\right)$ wholesale price regulation is that it causes both retail prices to fall. Thus (in the analogue of Lemma 5) the price effect on aggregate pay-TV consumer surplus is positive - all type 1 and 2 consumers are better off, if there is no quality effect. However the quality effect is now always negative, even in the QDE case. The reason comes from the duality result discussed earlier. b1's laissez-faire wholesale price is $h_{1}=\frac{1}{2} v$, and increases with $T$, via $v$. By duality the SPE value of $T$ now definitely falls as wholesale price regulation is imposed just below $h_{1}^{*}$, this quality effect offsetting to some extent at least the positive price effect on aggregate pay-TV consumer surplus, and certainly causing all stadium consumers, club owners and players to be worse off. There remains no strong welfare case for wholesale regulation of QDE, and its consequences in $\mathrm{RDE}$ are completely analogous to those for margin regulation in RDE.

The fact that price effects of wholesale price regulation are better than for margin regulation generalises. The idea is illustrated in Figure 6. Given $T$, suppose (on some specification of

27 From (4.1) $d \pi_{1 W} / d m_{R}=\frac{1+\varepsilon}{\varepsilon} T^{\sigma-1} \frac{d T}{d m_{R}}\left\{\eta\left(\alpha+\beta_{1}+\frac{2+\delta}{2+2 \delta} \beta_{2}\right)-T^{\frac{1}{\varepsilon}+1-\sigma}\right\}$. In RDE, $\frac{d T}{d m_{R}}<0$ and it follows that $d \pi_{1 W} / d m_{R}>0$ if $\eta\left(\alpha+\beta_{1}+\frac{2+\delta}{2+2 \delta} \beta_{2}\right)<T^{\frac{1}{\varepsilon}+1-\sigma}$. But, using (3.12), this inequality holds since $T>\hat{T}_{1}$.

${ }^{28}$ Two previous contributions provide a similar comparison. Armstrong and Vickers (1998) consider the access price regulation of a dominant integrated firm that competes in the retail sector with a competitive fringe. Input quality is exogenously given. Similar to our findings, the authors show that wholesale price regulation performs better (both in terms of welfare and profits of the competitive fringe) than margin regulation. The intuition is that under wholesale price regulation the integrated firm chooses a lower retail price since an increase in the price would have a direct positive effect on the fringe's quantity supply. Our model is richer than the one described in Armstrong and Vickers (1998). In particular in our framework all firms behave strategically in the retail sector and access price regulation produces effects both on the quality of the input (i.e. the sports talent) and subscription prices. Weeds (2011) too compares margin and wholesale price regulation, but her interest lies only on the effects that regulation has on (downstream and upstream) quality investments. She shows that margin regulation induces higher investments compared to wholesale price regulation. 
pay-TV demands) that laissez-faire stage III subgame equilibrium has b1 choosing $\left(s_{1}^{*}, h_{1}^{*}\right)$, anticipating $s_{2}^{*}=s_{2}\left(s_{1}^{*}, h_{1}^{*}\right)$. Suppose (as in our pay-TV demand specification) that b1's profit function (anticipating $s_{2}=s_{2}\left(s_{1}, h_{1}\right)$ ), is $C^{2}$ and strictly quasi-concave on some neighbourhood of $\left(s_{1}^{*}, h_{1}^{*}\right)$, a neighbourhood that includes the b1 profit contour shown. Then after the imposition of margin regulation at $m_{R}$, b1 chooses $\hat{s}_{1}, \hat{h}_{1}$, anticipating $\hat{s}_{2}=s_{2}\left(\hat{s}_{1}, \hat{h}_{1}\right)$. Compare this with the imposition of wholesale price regulation at $h_{R}$ which leads b1 to choose $\hat{\hat{s}}_{1}<\hat{s}_{1}, \hat{\hat{h}}_{1} \equiv h_{R}<\hat{h}_{1}$. Under quite general specifications (including ours), $s_{2}\left(s_{1}, h_{1}\right)$ is increasing in both $h_{1}$ and $s_{1}$; it follows that $\hat{\hat{s}}_{2} \equiv s_{2}\left(\hat{\hat{s}}_{1}, \hat{\hat{h}}_{1}\right)<\hat{s}_{2}$. Both retail prices are lower under the $h_{R}$ regulation than under $m_{R}$, and all pay-TV consumers are better off with wholesale price regulation.

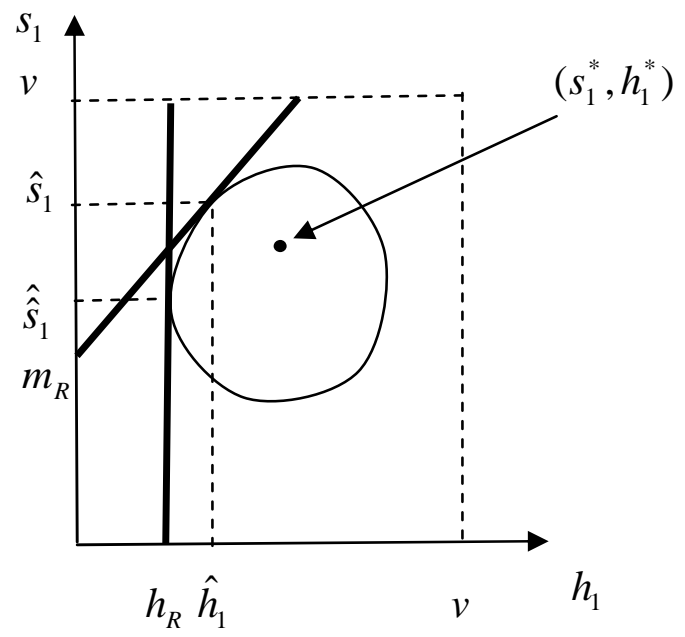

Figure 6: wholesale versus margin regulation

\section{CONCLUSIONS}

Motivated by the history of EPL TV right's auctions, and Ofcom's (2010) suggested (WMO plus margin) regulation of the resulting Sky Sports pay-TV channel, a Game-theoretic model has been presented which integrates a broadcasting sector (with 2 broadcasters and pay-TV consumers) and a sports league (with 2 clubs and their owners, stadium consumers and players). A fundamental consequence of the integration is the distinction between qualitydriven and rival-driven auction outcomes (QDE and RDE), the former emerging when the highest bid is well in excess of the rival because the rights income provided will lead clubs to improve team, league, and hence channel quality, and the rival is happy to bid low and accept wholesale purchase of the higher quality channel. Whether QDE or RDE prevails under laissez-faire depends on a range of sports league/broadcasting sector parameters and auction protocol (QDE is impossible with SPSB), and does affect the consequences of regulation. We have speculated that some of the EPL auctions bear more the hallmarks of QDE than RDE.

With respect to the suggested regulation, 3 broad arguments were put forward by Ofcom (2010): (a) WMO is needed since the right's winner (Sky) may want to withhold from wholesaling negotiations under laissez-faire, i.e. foreclose on rival access to the resulting (Sky Sports) channel; (b) the proposed remedy should have little or no effect on auction bids and league rights income; (c) the proposed remedy should benefit pay-TV consumers. 
However, our theoretical model fails to find support for these arguments. On (a), a surprisingly general argument, surviving to any degree of pay-TV market competition, shows how the rights winner will always want to make a wholesale offer to the losing rival in our context, so WMO is redundant. In RDE, margin regulation typically causes reductions in league rights income, since it increases the payoff to losing the rights and buying wholesale, thus reducing the upward pressure on the winning bid, with more nuanced conclusions for QDE; neither offers much support for (b). And in (c), not only does the regulation reduce pay-TV consumer surplus, but it also reduces (at least weakly) welfare of all other interested parties (stadium consumers, club owners, players), except possibly and perversely the broadcasters themselves.

Moreover, although we reiterate the ability of direct wholesale price regulation to dominate margin regulation in terms of its price effects on pay-TV consumers quite generally in the context, this alternative regulation format is more disadvantageous in its adverse effects on league rights income than margin regulation; direct wholesale price regulation thus produces different but not unambiguously better conclusions. Following Harbord and Otaviani (2001, 2002), other possibilities, such as less exclusivity in the awarding of rights, a move away from collective sale by the EPL to individual club bargaining, or, more draconian, divesting the broadcasters are possible future topics for our integrated sports league/broadcaster framework. 


\section{APPENDIX}

Proof of Lemma 1 (a) It follows from (3.3) that in any stage II subgame equilibrium; $a_{1}\left(W_{1}\right) \equiv \mu_{1} d\left(W_{1}\right) / W_{1}=\mu_{2} d\left(1-W_{1}\right) /\left(1-W_{1}\right) \equiv a_{2}\left(W_{1}\right)$. As $d\left(W_{1}\right)$ is strictly concave and $d(0)=0, a_{1}^{\prime}\left(W_{1}\right)<0, a_{2}^{\prime}\left(W_{1}\right)>0$, for $W_{1} \in(0,1)$. Also $a_{1}\left(\frac{1}{2}\right)>a_{2}\left(\frac{1}{2}\right)$ as $\mu_{1}>\mu_{2}$. From the Inada condition on $d\left(W_{1}\right), \quad a_{2}\left(W_{1}\right) \rightarrow+\infty \quad$ as $\quad W_{1} \rightarrow 1 \quad$ and $\quad a_{1}(1)=\mu_{1} d(1)$. Thus $a_{1}\left(W_{1}\right)=a_{2}\left(W_{1}\right)$ has a unique solution $W_{1}^{*} \in\left(\frac{1}{2}, 1\right)$ that is independent of $b$.

(b) With $\alpha \equiv a_{1}\left(W_{1}^{*}\right)\left(=a_{2}\left(W_{1}^{*}\right)\right), b=T^{\frac{1+\varepsilon}{\varepsilon}}-\alpha T^{\sigma}$ from (3.3), defining an increasing function $b(T)=T^{\frac{1+\varepsilon}{\varepsilon}}-\alpha T^{\sigma}$ on domain $T \geq \alpha^{\frac{\varepsilon}{11+\varepsilon-\varepsilon \sigma}}$, and its inverse.

Proof of Lemma 2 The stationary point of (3.4) occurs at $s_{2}=\frac{1}{2} v+\frac{1}{2} h_{1}$ which is in the (3.4) domain if $s_{1} \geq a+\frac{1}{2+2 \delta} h_{1}$ where $a \equiv \frac{1+2 \delta}{2+2 \delta} v$ (otherwise the stationary point is to the right of the domain and $\pi_{b 2}$ is increasing on the (3.4) domain). The stationary point of (3.5) occurs at $s_{2}=\frac{\delta \beta_{2}}{2 \delta \beta_{2}+2 \beta_{1}} v+\frac{\beta_{1}}{2 \delta \beta_{2}+2 \beta_{1}} s_{1}+\frac{1}{2} h_{1}$ which is in the (3.5) domain if:

(i) $s_{1}<b+\frac{\delta \beta_{2}+\beta_{1}}{\beta_{1}+\delta\left(2 \delta \beta_{2}+2 \beta_{1}+2 \beta_{2}\right)} h_{1}$ where $b \equiv \frac{\delta\left(2 \delta \beta_{2}+2 \beta_{1}+\beta_{2}\right)}{\beta_{1}+\delta\left(2 \delta \beta_{2}+2 \beta_{1}+2 \beta_{2}\right)} v$ (otherwise the stationary point is to the left of the domain and $\pi_{b 2}$ is decreasing on the (3.5) domain);

(ii) $s_{1} \geq d+\frac{\delta \beta_{2}+\beta_{1}}{2 \delta \beta_{2}+\beta_{1}} h_{1}$ where $d \equiv \frac{\delta \beta_{2}}{2 \delta \beta_{2}+\beta_{1}} v$ (otherwise the stationary point is to the right of the domain and $\pi_{b 2}$ is increasing on the (3.5) domain).

The stationary point of (3.6) occurs at $s_{2}=\frac{\delta}{2+2 \delta} v+\frac{1}{1+2 \delta} s_{1}+\frac{1}{2} h_{1}$ which is in the (3.6) domain if:

(iii) $s_{1} \leq c+\frac{1+\delta}{1+2 \delta} h_{1}$ where $c=\frac{\delta}{1+2 \delta} v$ (otherwise the stationary point is to the left of the domain and $\pi_{b 2}$ is decreasing on the (3.6) domain);

(iv) $h_{1}<e+\frac{1}{1+\delta} s_{1}$ where $e=\frac{\delta}{1+\delta} v$ (otherwise the stationary point is to the right of the domain and $\pi_{b 2}$ is increasing on the (3.6) domain).

It follows straightforwardly, and as shown in Figure 1, that $a>b>c>d$.

If $\left(s_{1}, h_{1}\right)$ is in region A of Figure 1, then b2's best response is at the (3.4) stationary point $s_{2}=\frac{1}{2} v+\frac{1}{2} h_{1}$, in the (3.4) domain with $\pi_{b 2}$ decreasing everywhere to the right of this domain. If $\mathrm{b} 1$ chose $\left(s_{1}, h_{1}\right)$ in region $\mathrm{A}$, it gets no retail revenue and (ignoring the sunk winning bid costs $) \pi_{b 1}=h_{1} D_{b 2}=\left(\beta_{2}+\frac{1}{1+\delta} \beta_{1}\right) h_{1}\left(\frac{1}{2} v-\frac{1}{2} h_{1}\right)$, maximized with $h_{1}=\frac{1}{2} v$ giving $\pi_{b 1}^{A} \equiv \frac{1}{8}\left(\beta_{2}+\frac{1}{1+\delta} \beta_{1}\right) v^{2}$.

For $\left(s_{1}, h_{1}\right)$ in region $\mathrm{B}$, b2's best response is always at the right end of the (3.4) domain, since $\pi_{b 2}$ is increasing to the left of this point and decreasing everywhere to the right (so the maximum is at a kink in $\pi_{b 2}$ ). Again b1 will get no retail revenue and

$h_{1}=\frac{1}{2} v, \pi_{b 1}^{A}$ is the best b1 can do. Thus b1's optimal choice over $\left(s_{1}, h_{1}\right)$ in A or B gives $\pi_{b 1}^{A}=\frac{1}{8}\left(\beta_{2}+\frac{1}{1+\delta} \beta_{1}\right) v^{2}$ with $h_{1}=\frac{1}{2} v$ and any $s_{1}$ such that $\left(s_{1}, \frac{1}{2} v\right)$ is in A or B.

b1 would get only retail revenue from choice of $\left(s_{1}, h_{1}\right)$ in $\mathrm{E}$, giving $\pi_{b 1}=s_{1} D_{b 1}=\left(\beta_{1}+\frac{1}{1+\delta} \beta_{2}\right) s_{1}\left(v-s_{1}\right), \quad$ maximized with $s_{1}=\frac{1}{2} v \quad$ and $\pi_{b 1}^{E} \equiv \frac{1}{4}\left(\beta_{1}+\frac{1}{1+\delta} \beta_{2}\right) v^{2}>\pi_{b 1}^{A}$. Thus b1's optimal choice over $\left(s_{1}, h_{1}\right)$ in $\mathrm{A}$, B or $\mathrm{E}$ gives $\pi_{b 1}^{E}=\frac{1}{4}\left(\beta_{1}+\frac{1}{1+\delta} \beta_{2}\right) v^{2}$, with $s_{1}=\frac{1}{2} v$ and any $h_{1}$ such that $\left(\frac{1}{2} v, h_{1}\right)$ is in E.

Consider next $\left(s_{1}, h_{1}\right)$ in D. b2's best response is at the (3.6) stationary point $s_{2}=\frac{\delta}{2+2 \delta} v+\frac{1}{1+2 \delta} s_{1}+\frac{1}{2} h_{1}$, in the (3.6) domain with $\pi_{b 2}$ increasing everywhere to the left of 
this domain and decreasing everywhere to the right. Substituting into $\pi_{b 1}=s_{1}\left[\beta_{1}\left(v-s_{1}\right)+\frac{1}{\delta} \beta_{2}\left(s_{2}-s_{1}\right)\right]+h_{1} \beta_{2}\left[v-s_{2}-\frac{1}{\delta}\left(s_{2}-s_{1}\right)\right]$ produces a concave function of $\left(s_{1}, h_{1}\right)$ whose global maximum is straightforwardly shown to be $s_{1}=h_{1}=\frac{1}{2} v$, which is in D and gives $\pi_{b 1}^{D} \equiv \frac{1}{4}\left(\beta_{1}+\frac{2+\delta}{2+2 \delta} \beta_{2}\right) v^{2}>\pi_{b 1}^{E}$ since $\delta>0$. Since $\pi_{b 1}^{E}$ is the maximum profit attainable by b1 if foreclosure of b2 was chosen, it follows that foreclosure never occurs in stage III subgame equilibrium.

Now consider region C. Here b2's best response is at the (3.5) stationary point $s_{2}=\frac{\delta \beta_{2}}{2 \delta \beta_{2}+2 \beta_{1}} v+\frac{\beta_{1}}{2 \delta \beta_{2}+2 \beta_{1}} s_{1}+\frac{1}{2} h_{1}$, in the (3.5) domain with $\pi_{b 2}$ increasing everywhere to the left of this domain and decreasing everywhere to the right. B1's profit is now $\pi_{b 1}=s_{1} \beta_{1}\left[v-s_{1}-\frac{1}{\delta}\left(s_{1}-s_{2}\right)\right]+h_{1}\left[\beta_{2}\left(v-s_{2}\right)+\frac{1}{\delta} \beta_{1}\left(s_{1}-s_{2}\right)\right]$. Let $\Delta$ be the difference between this $\pi_{b 1}$ and the corresponding $\pi_{b 1}$ expression in the last paragraph for region $\mathrm{D}$ : $\Delta=\frac{1}{\delta}\left(s_{1}-h_{1}\right)\left(s_{1}-s_{2}\right)\left(\beta_{2}-\beta_{1}\right)<0$ in region $\mathrm{C}$ when $s_{2}=\frac{\delta \beta_{2}}{2 \delta \beta_{2}+2 \beta_{1}} v+\frac{\beta_{1}}{2 \delta \beta_{2}+2 \beta_{1}} s_{1}+\frac{1}{2} h_{1}$, since $s_{1}>h_{1}, s_{1}>s_{2}$, but $\beta_{2}<\beta_{1}$. Thus the maximum profits attainable by a b1 choice in region $\mathrm{C}$ given b2's best response must be less than $\pi_{b 1}^{D}$ from the global maximum property of $\pi_{b 1}^{D}$.

In region $\mathrm{C} / \mathrm{D}$ in Figure $1 \mathrm{~b} 2$ 's profit function has 2 stationary points, one at $s_{2}=\frac{\delta \beta_{2}}{2 \delta \beta_{2}+2 \beta_{1}} v+\frac{\beta_{1}}{2 \delta \beta_{2}+2 \beta_{1}} s_{1}+\frac{1}{2} h_{1}$ (as in region C) and one at $s_{2}=\frac{\delta}{2+2 \delta} v+\frac{1}{1+2 \delta} s_{1}+\frac{1}{2} h_{1}$ (as in D).

The larger of these values will decide b2's best response. However whichever it is, the global maximum property of $\pi_{b 1}^{D}$ ensures that the resulting b1 profit level will be less than $\pi_{b 1}^{D}$, either directly (D) or from the above argument for C. It follows that the stage III subgame equilibrium entails a wholesale offer by b1 with $s_{1}=h_{1}=\frac{1}{2} v$ and b1 profits of $\pi_{b 1}^{D}$ (where the winning bid costs are reinstated in the Lemma 2 statement). From (3.6), b2 profits are $\pi_{b 2}=\left(s_{2}-h_{1}\right) \beta_{2}\left[\left(v-s_{2}\right)-\frac{1}{\delta}\left(s_{2}-s_{1}\right)\right]$ which becomes $\pi_{b 2}=\frac{\delta}{16+16 \delta} \beta_{2} v^{2}$ with the appropriate substitutions.

Proof of Lemma 3 The proof of Lemma 2 suffices with 2 changes. First all1/2 subscripts are interchanged. Secondly, the argument relating to the right's winner's attainable profit in region $\mathrm{C} / \mathrm{D}$ is changed as follows. In this region the loser (now b1) best response occurs at a kink in their profit function where $s_{1}=s_{2}$, producing winner profit of $\pi_{b 2}=s_{2} \beta_{2}\left(v-s_{2}\right)$ which is bounded above by the region $\mathrm{E}$ (foreclosure) profit, shown already to be less than that attainable in region D. The result follows.

Proof of Proposition 1 Firm 1's foreclosure pricing problem is; $\max _{s_{1}}\left(s_{1}-c\right) Q_{1 f}\left(s_{1}\right)$ subject to $s_{1} \in \mathfrak{R}_{+}$

From (A2), $Q_{1 f}\left(s_{1}\right)=Q_{1}\left(s_{1}, v\right)$ for all $s_{1} \in \mathfrak{R}_{+}$, defining from (A1) the continuous function $Q_{1 f}: \Re_{+} \rightarrow \Re_{+}$. Since $s_{1}<c_{1}$ or (from (A2)) $s_{1}>v$ give non-positive profits and since positive profits are attainable at some $s_{1}>c_{1}$, from (A4), the feasible set for the foreclosure pricing problem can be truncated to $s_{1} \in\left[c_{1}, v\right]$. From Weierstrass' Theorem, the problem has a solution, at some $s_{1}^{*}>c_{1}$ with $\Pi_{1}^{*}>0$. If $Q_{2}\left(s_{1}^{*}, s_{1}^{*}\right)=0$ then $Q_{1 f}\left(s_{1}^{*}\right)=Q_{1}\left(s_{1}^{*}, s_{1}^{*}\right)=0$ from (A3) and (A6), contradicting $\Pi_{1}^{*}>0$; thus $Q_{2}\left(s_{1}^{*}, s_{1}^{*}\right)>0$.

Consider now the wholesale offer by firm 1 of $h_{1}=s_{1}^{*}-c_{1}$ with $s_{1}=s_{1}^{*}$. Firm 1's profit will be $\Pi_{1}\left(s_{2}\right) \equiv\left(s_{1}^{*}-c_{1}\right) Q\left(s_{1}^{*}, s_{2}\right)$ and that of firm $2 \Pi_{2}\left(s_{2}\right) \equiv\left(s_{2}-s_{1}^{*}+c_{1}-c_{2}\right) Q_{2}\left(s_{1}^{*}, s_{2}\right)$, depending on firm 2's choice of $s_{2}$. 
Let $\hat{s}_{2} \equiv \max \left[0, s_{1}^{*}-c_{1}+c_{2}\right] \leq s_{1}^{*} ; \Pi_{2}\left(s_{2}\right) \leq 0$ if $s_{2} \leq \hat{s}_{2}$. Also, from (A5), $\Pi_{2}\left(s_{2}\right) \leq 0$ if $s_{2} \geq \bar{s}_{2}\left(s_{1}^{*}\right)>s_{1}^{*}$. But firm 2 can attain positive profits from some $s_{2} \in\left(\hat{s}_{2}, \bar{s}_{2}\left(s_{1}^{*}\right)\right)$ from (A1), since $Q_{2}\left(s_{1}{ }^{*}, s_{1}^{*}\right)>0$. Firm 2's best response problem can now be written as $\max _{s_{2}} \Pi_{2}\left(s_{2}\right)$ subject to $s_{2} \in\left[\hat{s}_{2}, \bar{s}_{2}\left(s_{1}^{*}\right)\right]$, which must have a solution (Weierstrass), $s_{2}^{*}$ say, where $s_{2}^{*} \in\left(\hat{s}_{2}, \bar{s}_{2}\left(s_{1}^{*}\right)\right)$.

$\Pi_{1}\left(\bar{s}_{2}\left(s_{1}^{*}\right)\right)=\left(s_{1}^{*}-c_{1}\right) Q\left(s_{1}^{*}, \bar{s}_{2}\left(s_{1}^{*}\right)\right)=\left(s_{1}^{*}-c_{1}\right) Q_{1 f}\left(s_{1}^{*}\right)$ since $Q_{2}\left(s_{1}^{*}, \bar{s}_{2}\left(s_{1}^{*}\right)\right)=0$, from (A5). Hence $\Pi_{1}\left(\bar{s}_{2}\left(s_{1}^{*}\right)\right)=\left(s_{1}^{*}-c_{1}\right) Q_{1 f}\left(s_{1}^{*}\right)=\Pi_{1}^{*}$.

But, from (A5) again, $\Pi_{1}\left(s_{2}\right)=\left(s_{1}^{*}-c_{1}\right) Q\left(s_{1}^{*}, s_{2}\right)>\Pi_{1}^{*}$ for all $s_{2} \in\left[\hat{s}_{2}, \bar{s}_{2}\left(s_{1}^{*}\right)\right)$. In particular, $\Pi_{1}\left(s_{2}^{*}\right)>\Pi_{1}^{*}$, and there always exists a wholesale offer that beats foreclosure for firm 1 .

The Game can be taken to have compact action sets $\left(s_{1}, s_{2}, h_{1} \in[0, v]\right)$, and continuous payoff functions. The (second stage) firm 2 problem will generate a correspondence that has a closed (and bounded) graph, from the Theorem of the Maximum. The reduced form first stage problem for firm 1 then requires the maximum of a continuous function on a compact set, which exists, by Weierstrass, ensuring existence of subgame perfect equilibrium.

Proof of Corollary to Proposition 1 Adopting the notation of the proof of Proposition 1, neither $s_{1}^{*}$ nor $\bar{s}_{2}\left(s_{1}^{*}\right)\left(>s_{1}^{*}\right)$ depend on $c_{2}$. Define $\varepsilon^{*} \equiv \bar{s}_{2}\left(s_{1}^{*}\right)-s_{1}^{*}$. If $c_{2}=c_{1}+\varepsilon$ then $\hat{s}_{2}=s_{1}^{*}+\varepsilon \in\left(s_{1}^{*}, \bar{s}_{2}\left(s_{1}^{*}\right)\right)$ if $\varepsilon \in\left(0, \varepsilon^{*}\right)$. The arguments of Proposition 1 can be applied: firm 2 's best response will lie in $\left(\hat{s}_{2}, \bar{s}_{2}\left(s_{1}^{*}\right)\right)$; as $s_{2}$ increases in this interval, $\Pi_{1}\left(s_{2}\right)$ decreases towards $\Pi_{1}^{*}$ at $\bar{s}_{2}\left(s_{1}^{*}\right)$. The result follows.

Proof of Proposition 2 Given $b_{2}^{*} \leq b(Z)$, b1 does not wish to increase its bid, as it wins, with higher $T$ and lower $\pi_{1 W}(T)$. b1 does not wish to reduce its bid but still above (or equal to) $b_{2}^{*}$, as it wins with lower $T$ and lower $\pi_{1 W}(T)$. If b1 reduced its bid below $b_{2}^{*}$ it would lose; but as $b_{2}^{*}<b(Z)$, b1's payoff on $\pi_{1 L}(T)$ would be below $\pi_{1}^{*}$. Given $b_{1}^{*}$, b2 does not wish to deviate to any other $b_{2} \in\left[0, b_{1}^{*}\right]$ since b2 loses with unchanged payoff. $b_{2}>b_{1}^{*}$ means b2 wins but gets less than $\pi_{2}^{*}$, on $\pi_{2 W}(T)$.

Proof of Proposition 3 With $b_{1}^{*}=b_{2}^{*}=b(T)$, b1 does not wish to increase its bid (it still would win the rights with a higher $T$ but with a lower payoff along $\pi_{1 W}(T)$ ), or to reduce its bid (it now loses, with lower payoff $\pi_{1 L}(T)<\pi_{1}^{*}$ ). b2 does not wish to reduce its bid (it still loses with unchanged payoff), or increase it (since $T_{1}^{*}>\bar{T}_{2}$ ensures a lower, winning payoff, along $\pi_{2 W}(T)$ ). If $T=\hat{T}_{1}$, b2 would be indifferent to any lower bid than $b_{2}^{*}$, and b1 would still best respond with $b\left(\hat{T}_{1}\right)$

Proof of Proposition 4 With $b_{1}^{*}=b_{2}^{*}=b(T)$, b1 does not wish to increase its bid (it still wins, with a higher $T$ and lower payoff along $\pi_{1 W}(T)$ ), or reduce it (it loses, with lower payoff $\left.\pi_{1 L}(T)<\pi_{1}^{*}\right)$. b2 does not wish to reduce its bid (it still loses with unchanged payoff), or increase it (producing a lower, winning payoff, along $\pi_{2 W}(T)$ ).

Proof of Proposition 5 There can be no equilibrium with different bids - the loser (bi say) can improve by raising its strictly lower (second price) bid, increasing $T$ and $\pi_{i L}(T)$. If $b_{1}=b_{2}=b(T)$ and $T<\tilde{T}_{2}$ then $\mathrm{b} 2$ can improve by an increase in its bid so it wins paying b1's (now) second-price bid with unchanged league quality. If $b_{1}=b_{2}=b(T)$ and $T>\tilde{T}_{1}$, 
then b1 can improve with a lower bid, so it loses, b2 paying b1's (now) second-price bid, $T$ falling a little but still beneficially for b1 since $\pi_{1 L}(T)>\pi_{1 W}(T)$. If $b_{1}=b_{2}=b(T)$ and $T \in\left[\tilde{T}_{2}, \tilde{T}_{1}\right]$, there is no benefit to b1 in raising its bid (it stills wins with the same payment and quality) or in lowering its bid (it loses with lower profit on $\pi_{1 L}(T)$ ). b2 also cannot benefit from an increase in its bid (it wins with unchanged quality) or a decrease (it still loses but quality falls).

Proof of Lemma 4 (a) Under laissez-faire b1 profit in region D was;

$\pi_{b 1}=s_{1}\left[\beta_{1}\left(v-s_{1}\right)+\frac{1}{\delta} \beta_{2}\left(s_{2}-s_{1}\right)\right]+h_{1} \beta_{2}\left[v-s_{2}-\frac{1}{\delta}\left(s_{2}-s_{1}\right)\right]$

where $s_{2}=\frac{\delta}{2+2 \delta} v+\frac{1}{1+2 \delta} s_{1}+\frac{1}{2} h_{1}$. The global maximum of this concave function over $\left(s_{1}, h_{1}\right) \in[0, v]^{2}$ was at $s_{1}=h_{1}=\frac{1}{2} v$, as reported in the proof of Lemma 2. The maximum of this function subject to the constraint $s_{1}-h_{1} \geq m_{R}$, for small positive $m_{R}$, will satisfy $h_{1}=s_{1}-m_{R}$, and the solution value for $s_{1}$ maximizes the following concave function of $s_{1}$, found by substituting $s_{2}=\frac{\delta}{2+2 \delta} v+\frac{1}{1+2 \delta} s_{1}+\frac{1}{2} h_{1}$ and $h_{1}=s_{1}-m_{R}$ into the above $\pi_{b 1}$ expression;

$$
\pi_{b 1}=s_{1}\left[\left(\beta_{1}+\frac{1}{2+2 \delta} \beta_{2}\right)\left(v-s_{1}\right)-\frac{1}{2 \delta} \beta_{2} m_{R}\right]+\left(s_{1}-m_{R}\right) \beta_{2}\left[\frac{1}{2}\left(v-s_{1}\right)+\frac{1+\delta}{2 \delta} m_{R}\right]
$$

The stationary point required is at the value of $s_{1}$ reported in Lemma 4(a), and the reported values for $h_{1}=s_{1}-m_{R}, s_{2}=\frac{\delta}{2+2 \delta} v+\frac{1}{1+2 \delta} s_{1}+\frac{1}{2} h_{1}$ and $\pi_{b 1}$ follow on substituting this $s_{1}$. The region $\mathrm{D}$ formula for $\mathrm{b} 2$ profit is;

$\pi_{b 2}\left(s_{2}, s_{1}, v, h_{1}\right)=\left(s_{2}-h_{1}\right) \beta_{2}\left[\left(v-s_{2}\right)-\frac{1}{\delta}\left(s_{2}-s_{1}\right)\right]$

Substitution of the calculated $s_{1}, h_{1}$ and $s_{2}$ values gives the Lemma 4(a) statement. The argument in the text completes the proof.

(b) This follows from (a) in the same way as Lemma 3 followed from Lemma 2.

Proof of Proposition 6 Follows as in the proofs of Propositions 2-5.

Proof of Lemma 5 Let $s_{1}(v, m)$ and $s_{2}(v, m)$ be as defined in Lemma 4(a), and denote partial derivatives by subscripts $\left(s_{i v}\right.$ for $\partial s_{i} / \partial v, s_{i m}$ for $\partial s_{i} / \partial m$ ) where $m=m_{R}$. Let $v=v(m)$ be a differentiable function reflecting the dependence of league quality ( $T$ and so $v$ ) on the regulated margin. Differentiating (5.1) gives;

$$
\begin{aligned}
d C S_{b} / d m= & \beta_{1}\left(v-s_{1}\right)\left[v^{\prime}(m)\left(1-s_{1 v}\right)-s_{1 m}\right]+\beta_{2}\left(v-s_{2}\right)\left[v^{\prime}(m)\left(1-s_{2 v}\right)-s_{2 m}\right] \\
& +\frac{1}{2 \delta} \beta_{2}\left(s_{2}-s_{1}\right)\left[v^{\prime}(m)\left(s_{2 v}-s_{1 v}\right)+s_{2 m}-s_{1 m}\right]=K v^{\prime}(m)-L
\end{aligned}
$$

where $K=\beta_{1}\left(v-s_{1}\right)\left(1-s_{1 v}\right)+\beta_{2}\left(v-s_{2}\right)\left(1-s_{2 v}\right)+\frac{1}{2 \delta} \beta_{2}\left(s_{2}-s_{1}\right)\left(s_{2 v}-s_{1 v}\right)$

and $\quad L=\beta_{1}\left(v-s_{1}\right) s_{1 m}+\beta_{2}\left(v-s_{2}\right) s_{2 m}+\frac{1}{2 \delta} \beta_{2}\left(s_{2}-s_{1}\right)\left(s_{2 m}-s_{1 m}\right)$

Let $M \equiv \frac{\beta_{2}(1+\delta)}{2 \beta_{1}(1+\delta)+\beta_{2}(2+\delta)}$ so that $s_{1}=\frac{1}{2} v+M m$ and $s_{1 m}=M, s_{1 v}=\frac{1}{2}$, and let $N \equiv \frac{\beta_{1}(1+\delta)}{2 \beta_{1}(1+\delta)+\beta_{2}(2+\delta)}$ so that $s_{2}=\frac{2+3 \delta}{4+4 \delta} v-N m$ and $s_{2 m}=-N, s_{2 v}=\frac{2+3 \delta}{4+4 \delta}$.

Substituting into the $K$ expression, with $m=0$, gives $K=v\left\{\frac{1}{4} \beta_{1}+\left[\frac{2+\delta}{8+8 \delta}+\frac{\delta}{(4+4 \delta)^{2}}\right] \beta_{2}\right\}$ and $K>0$. Doing the same for $L$ gives $L=v\left\{\frac{1}{2} \beta_{1} M-\frac{2+\delta}{4+4 \delta} \beta_{2} N+\frac{1}{4+4 \delta} \beta_{2}(M+N)\right\}$, and after inserting the $M, N$ expressions $L=v \frac{1}{4} \beta_{2} \frac{\beta_{1} \delta+\left(\beta_{1}+\beta_{2}\right)(1+\delta)}{2 \beta_{1}(1+\delta)+\beta_{2}(2+\delta)}>0$. 


\section{REFERENCES}

Armstrong, M., (1999), "Competition in the pay-TV market", Journal of the Japanese and International Economies, vol. 13, 257-280.

Armstrong, M., (2005), "Public service broadcasting", Fiscal Studies, vol. 26(3), p. 281-299.

Armstrong, M., (2002), "The theory of access pricing and interconnection", in Cave, M. E., Majumdar, S. K. and Vogelsang, I. eds., Handbook of telecommunications I, North-Holland, 297-384.

Armstrong, M., and Sappington, D., (2007), "Recent developments in the theory of regulation", in M. Armstrong and R. Porter (eds.), Handbook of Industrial Organization Vol. 3, Elsevier North-Holland.

Armstrong, M. and Vickers, J., (1998), "The Access Pricing Problem with Deregulation: A note", The Journal of Industrial Economics, vol. 46, 115-121.

Armstrong, M. and Weeds, H., (2007), "Public service broadcasting in the digital world", in The Economic Regulation of Broadcasting Markets: Evolving Technology and Challenges for Policy, P. Seabright and J. von Hagen (eds.), Cambridge University Press.

Bourreau, M., Hombert, J., Pouyet, J., and Schutz, N., (2011), "Upstream competition between vertically integrated firms", Journal of Industrial Economics, vol. 59(4), p. 677-713.

Buraimo, B., and Simmons, R., (2009), "A tale of two audiences: spectators, television viewers and outcome uncertainty in Spanish football", Journal of Economics and Business, vol. 61, 326-338.

CAT, (2012), Non-confidential extract from judgment, 8 August 2012.

The decision of the Competition Appeal Tribunal and the related documents can be found at: http://www.catribunal.org.uk/237-6549/1158-8-3-10-British-Sky-Broadcasting-Limited.html

Cave, M., and Crandall R.W., (2001), "Sports rights and the broadcast industry", Economic Journal, vol. 111, F4-F26.

Dietl, H.M., Lang, M. and Werner, S., (2009), "Social welfare in a sports league with profitmaximizing and win-maximizing clubs", Southern Economic Journal, vol. 76(2), 375-396.

Ettinger, D., (2010), "Bidding among friends and enemies with symmetric information", Journal of Institutional and Theoretical Economics, vol. 166(2), 365-385.

Falconieri, S., Palomino, F. and Sakovics, J., (2004), "Collective versus individual sale of television rights in league sports", Journal of the European Economic Association, vol. 2(5), 833-862.

Garcia-del-Barrio, P., and Szymanski, S., (2009), "Goal! Profit maximization versus win maximization in soccer", Review of Industrial Organization, vol. 34, 45-68.

Gratton, C. and Solberg, H. A., (2007), "The economics of professional sport and the media", European Sport Management Quarterly, vol. 7(4), 307-310. 
Harbord, D. and Ottaviani, M., (2001), "Contracts and competition in the pay-TV market", mimeo.

Harbord, D. and Ottaviani, M., (2002), "Anticompetitive contracts in the UK pay-TV market”, European Competition Law Review, vol. 23(3), 122-126.

Harbord, D. and Szymanski, S., (2004), "Football trials", European Competition Law Review, vol. 25(2), 117-122.

Hoffler, F. and Schmidt, K., (2008), “Two tales on resale", International Journal of Industrial Organization, vol. 26, 1448-1460.

Hombert, J., Pouyet, J., and Schutz, N., (2009), "Vertical integration, foreclosure and upstream competition", mimeo.

Horsman, M., (1998), Sky High: Orion, London.

Jeanrenaud, C. and Kesenne, S., (2006), The Economics of Sport and the Media: Edward Elgar, Cheltenham.

Jehiel, P. and Moldovanu, B., (2006), "Allocative and informational externalities in auctions and related mechanisms", in The Proceedings of the $9^{\text {th }}$ World Congress of the Econometric Society, R. Blundell, W. Newey, and T. Persson (eds.), Cambridge University Press.

Kesenne, S., (2007), The Economic Theory of Professional Team Sports; an Analytical Treatment: Edward Elgar.

Laffont, J.-J. and Tirole, J., (2000), "Competition in telecommunications", Cambridge, MIT Press.

Lang, M., Grossman, M. and Theiler, P., (2011), “The sugar daddy's game; how wealthy investors change competition in professional team sports", Journal of Institutional and Theoretical Economics, vol. 167(4), 557-577.

Lu, J., (2012), "Optimal auctions with asymmetric financial externalities", Games and Economic Behaviour, vol. 74(2), 561-75.

Maasland, E. and Onderstal, S., (2007), "Auctions with financial externalities", Economic Theory, vol. 32, 551-74.

Madden, P., (2011), "Game theoretic analysis of basic sports leagues", Journal of Sports Economics, Vol. 12(4), 407-431.

Madden, P., (2012), "Fan welfare maximization as a club objective in a professional sports league", European Economic Review, vol. 56, 560-578.

Madden, P., (2013), "Welfare economics of financial fair play in a sports league with benefactor owners", Journal of Sports Economics, forthcoming. 
Madden, P. and Pezzino, M., (2011), "Sports league quality, broadcaster TV rights income and price regulation of sports channels", paper presented to the EARIE conference, Stockholm, September 2011.

Madden, P. and Robinson, T., (2012), "Supporter influence on club governance in a sports league; a 'utility maximization' model", Scottish Journal of Political Economy, forthcoming.

Monopolies and Mergers Commission MMC, (1999), British Sky Broadcasting Group plc and Manchester United plc: The Stationery Office, London.

Ofcom, (2010), Pay-TV statement; non-confidential version, 31 March 2010.

Ordover, J. and Shaffer, G., (2007), "Wholesale access in multi-firm markets: when is it profitable to supply a competitor", International Journal of Industrial Organisation,vol. 25, 1026-1045.

Palomino, F. and Sakovics, J., (2004), "Inter-league competition for talent vs. competitive balance”, International Journal of Industrial Organisation,vol.22,783-97.

Sarmento, P. and Brandão, A., (2007), "Access Pricing: A comparison between full deregulation and two alternative instruments of access price regulationm, cost-based and retail-minus", Telecommunications Policy, vol. 31, 236-250.

Seabright, P. and Weeds, H., (2007), "Competition and market power in broadcasting; where are the rents?", in The Economic Regulation of Broadcasting Markets; Evolving Technology and Challenges for Policy, P. Seabright and J. von Hagen (eds.), Cambridge University Press.

Stennek, J., (2007), "Exclusive quality - why exclusive distribution may benefit the TV viewers", C.E.P.R. Discussion Paper No. 6072.

Szymanski, S. and Kuypers, T., (1999), Winners and Losers; the Business Strategy of Football: Viking.

Weeds, H., (2011), "Investment effects of price squeeze rules and margin regulation", mimeo, University of Essex. 